NASA

Technical

Memorandum

NASA TM - 103587

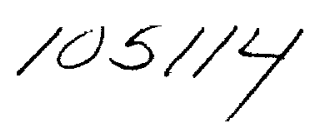

(NASA-TM-1035B7) ASSESSMENT OF A

N92-30381

HEAD-MUUNTED MINIATURE MONITOR

Final Report (NASA) $32 \mathrm{p}$

$63 / 54 \quad 0105114$

\title{
ASSESSMENT OF A HEAD-MOUNTED MINIATURE MONITOR
}

\section{Center Director's Discretionary Fund Final Report} (Project Number 89-07)

By J.P. Hale II

Mission Operations Laboratory

Science and Engineering Directorate

June 1992 
$\approx+.+$

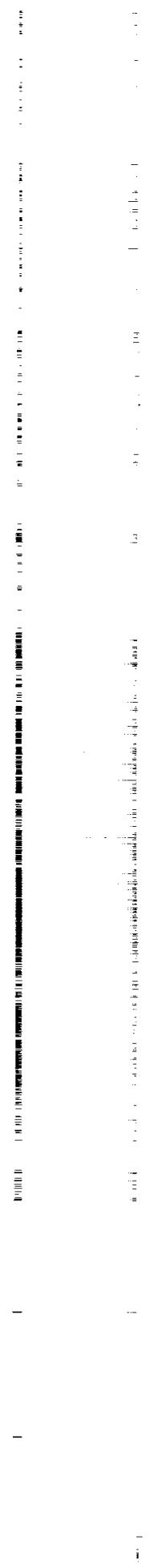


Public reporting burden for this collection of information is estimated to average i hour per response, including the time for reviewing instructions, searching existing data sources. gathering and maintaining the data needed, and completing and reviewing the collection of information. Send comments regarding this burden estimate or any other aspect of this

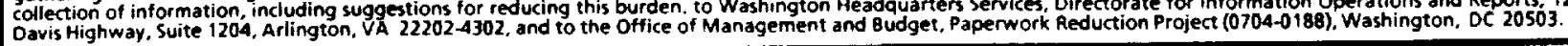
1. AGENCY USE ONLY (Leave blank)
2. REPORT DATE
June 1992
3. REPORT TYPE AND DATES COVERED
Technical Memorandum

\title{
4. TITLE AND SUBTITLE
}

Assessment of a Head-Mounted Miniature Monitor

Center Director's Discretionary Fund Final Report

(Project Number 89-07)

6. AUTHOR(S)

J.P. Hale II

7. PERFORMING ORGANIZATION NAME(S) AND ADDRESS(ES)

\section{George C. Marshall Space Flight Center}

Marshall Space Flight Center, Alabama 35812

9. SPONSORING/MONITORING AGENCY NAME(S) AND ADDRESS(ES)

National Aeronautics and Space Administration

Washington, DC 20546

8. PERFORMING ORGANIZATION REPORT NUMBER

\section{FUNDING NUMBERS}

\section{SUPPLEMENTARY NOTES}

Prepared by Mission Operations Laboratory, Science and Engineering Directorate

\author{
12a. DISTRIBUTION/AVAILABILITY STATEMENT \\ Unclassified-Unlimited
}

\section{ABSTRACT (Maximum 200 words)}

Two experiments were conducted to assess the capabilities and limitations of the Private Eye, a miniature, head-mounted monitor. The first experiment compared the Private Eye with a CRT and hard copy in both a constrained and unconstrained work envelope. The task was a simulated maintenance and assembly task that required frequent reference to the displayed information. A main effect of presentation media indicated faster placement times using the CRT as compared with hard copy. There were no significant differences between the Private Eye and either the CRT or hard copy for identification, placement, or total task times. The goal of the second experiment was to determine the effects of various local visual parameters on the ability of the user to accurately perceive the information of the Private Eye. The task was an interactive video game. No significant performance differences were found under either bright or dark ambient illumination environments nor with either visually simple or complex task backgrounds. Glare reflected off of the bezel surrounding the monitor did degrade performance. It was concluded that this head-mounted, miniature monitor could serve a useful role for in situ operations, especially in microgravity environments.

\begin{tabular}{|c|c|c|c|}
\hline \multirow{2}{*}{\multicolumn{3}{|c|}{$\begin{array}{l}\text { 14. SUBJECT TERMS } \\
\text { Private Eye, head-mounted display, miniature monitor, light- } \\
\text { emitting diode (LED) }\end{array}$}} & $\begin{array}{l}\text { 15. NUMBER OF PAGES } \\
39\end{array}$ \\
\hline & & & $\begin{array}{l}\text { 16. PRICE CODE } \\
\text { NTIS }\end{array}$ \\
\hline $\begin{array}{l}\text { 17. SECURITY CLASSIFICATION } \\
\text { OF REPORT } \\
\text { Unclassified }\end{array}$ & $\begin{array}{l}\text { 18. SECURITY CLASSIFICATION } \\
\text { OF THIS PAGE } \\
\text { Unclassified }\end{array}$ & $\begin{array}{l}\text { 19. SECURITY CLASSIFICATION } \\
\text { OF ABSTRACT } \\
\text { Unclassifled }\end{array}$ & $\begin{array}{l}\text { 20. LIMITATION OF ABSTRACT } \\
\text { Unlimited }\end{array}$ \\
\hline
\end{tabular}




\section{ACKNOWLEDGMENTS}

This research was supported by a Center Director's Discretionary Fund (No. 89-07) from the Marshall Space Flight Center. The author would like to thank those who administered these funds for the support and resources to conduct this research. The author also would like to thank Frankie Rice, a co-op student at MSFC, and Gina Klinzak, of New Technology, Inc., for their help in data collection in studies 1 and 2, respectively, and Julie Cosper, a co-op student at MSFC, for help in data collection in study 1 and data reduction and analysis in study 2. 


\section{TABLE OF CONTENTS}

Page

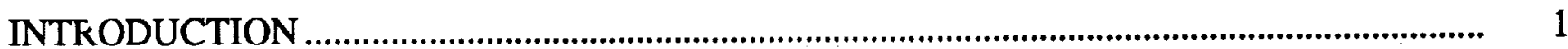

EXPERIMENT 1 1.......................................................................................................... 2

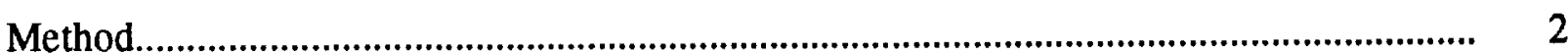

Overview ................................................................................................. 2

Design....................................................................................................... 2

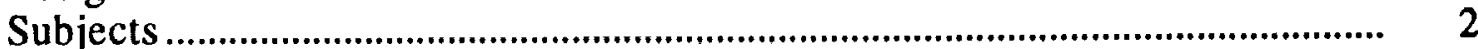

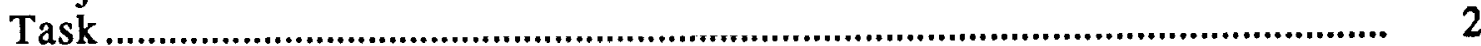

Materials and Apparatus.......................................................................................... 2

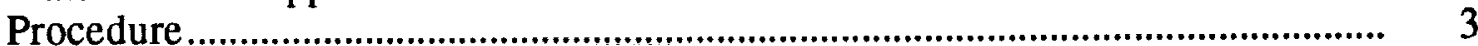

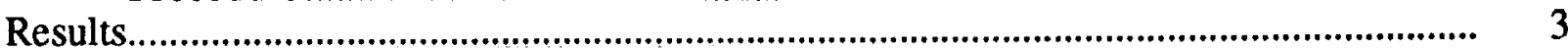

Discussion ............................................................................................................... 9

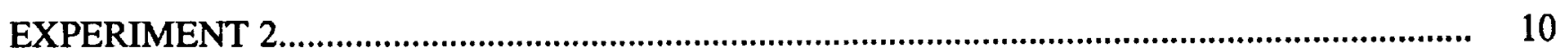

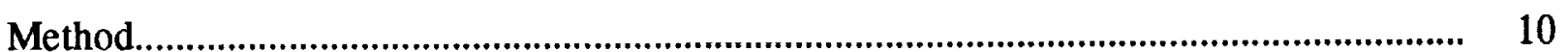

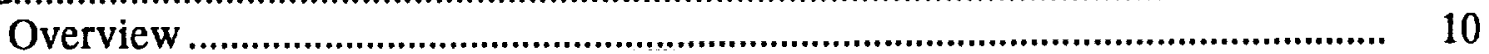

Design.......................................................................................................... 10

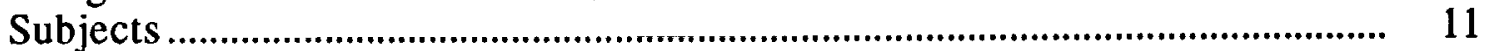

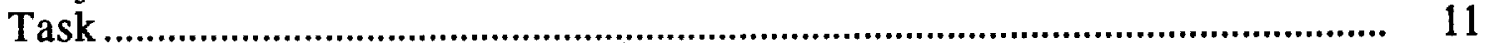

Materials and Apparatus................................................................................. 11

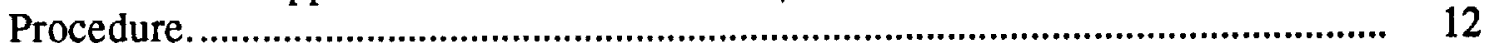

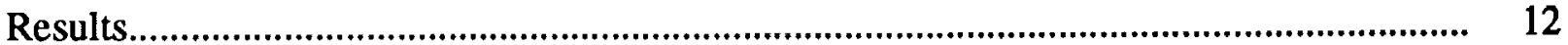

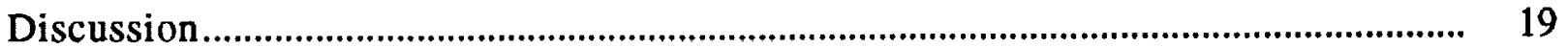

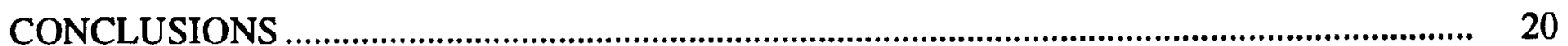

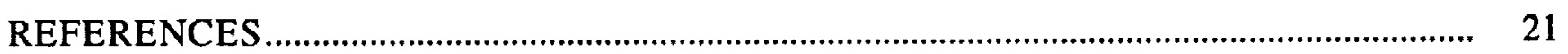

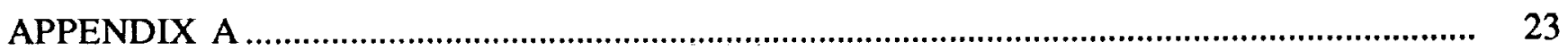

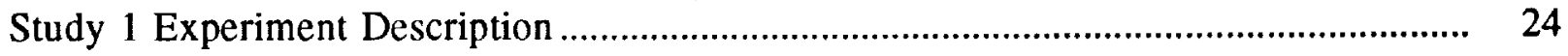

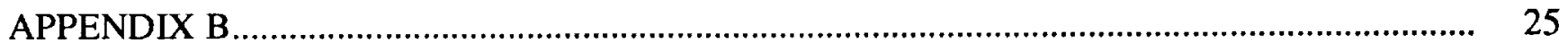

Informed Consent Form ........................................................................................ 26

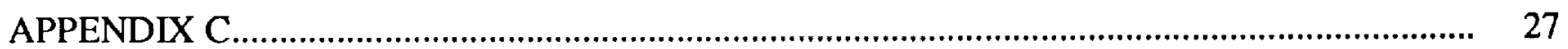

Study 2 Experiment Description ......................................................................................... 28

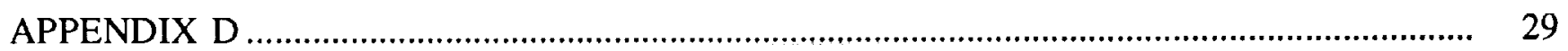

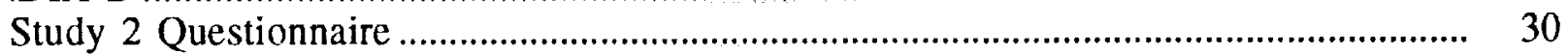




\section{LIST OF ILLUSTRATIONS}

Figure

Title

Page

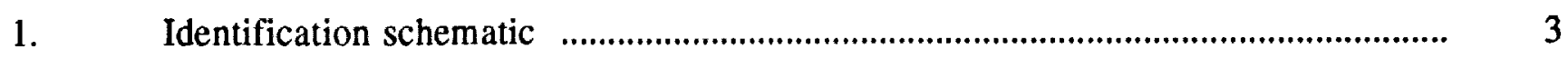

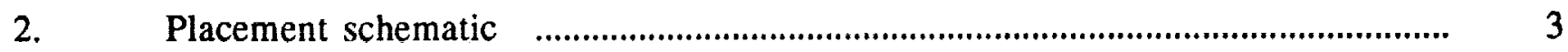

3. Cumulative placement time within trials as a function of presentation media $\quad \ldots . . . . \quad 5$

4. Identification time as a function of run number ……...................................................... 7

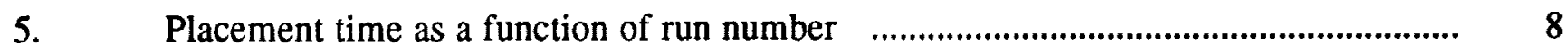

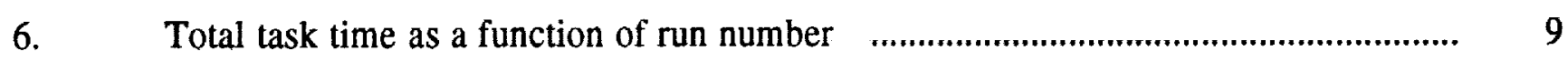

7. Mean score as a function of luminous surfaces (LS's) in the visual field ................... 14

8. Mean score as a function of ambient illuminator (AI), LS's in the visual field,

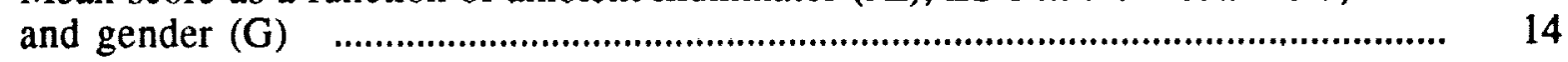

9. Mean score as a function of AI, background visual complexity (BVC), and G ........ 15 


\section{LIST OF TABLES}

Table

Title

Page

1. Analysis of variance (ANOVA) summary table for total task times

2. ANOVA summary table for identification times

4

3. ANOVA summary table for placement times ……………........................................... 5

4. Placement time as a function of presentation media ................................................... 5

5. ANOVA summary table for identification time .............................................................. 6

6. ANOVA summary table for placement time …............................................................... 6

7. ANOVA summary table for total task time ................................................................... 6

8. Identification time as a function of run number .................................................................

9. Placement time as a function of run number ...................................................................... 8

10. Total task time as a function of run number ..................................................................... 8

11. Illumination values for experimental conditions …………............................................. 12

12. ANOVA summary table for mean scores ..................................................................... 13

13. Mean score as a function of luminous surfaces ............................................................... 14

14. Mean score as a function of AI, LS, and G ................................................................ 14

15. Mean score as a function of AI, BVC, and G ........................................................... 15

16. ANOVA summary table for score ............................................................................ 16

17. Descriptive statistics for the questionnaire .................................................................. 16

18. Correlations among selected questions ...................................................................... 17

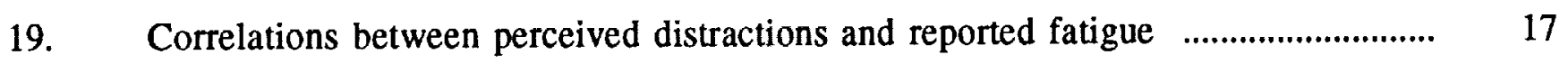

20. Correlations between $\mathrm{G}$ and selected questions ........................................................... 18

21. Correlations between session mean scores and questionnaire responses ................. 18 
TECHNICAL MEMORANDUM

\section{ASSESSMENT OF A HEAD-MOUNTED MINIATURE MONITOR}

\section{INTRODUCTION}

On Space Station Freedom (S.S. Freedom), there will be a need for a "portable workstation" to be used to access, among other things, electronically stored "owner's manuals" for in situ maintenance operations. Far too often, however, people tend to envision a "laptop" computer when they think of this "portable workstation."

In orbit, though, a laptop has some distinct disadvantages due to the unique microgravity environment. One disadvantage has to do with carrying the laptop to the work site. Holding it ties up a hand that would have been used for grabbing handholds and mobility aids along the translation route. Once the work site has been reached, another disadvantage becomes evident-the laptop must be restrained in a secure manner, otherwise it will float away. This requires a restraint assembly and a restraint attachment location on the surrounding structure. Ideally, these would place the monitor within, or at least near, the crewmember's task-centered cone-of-vision.

Unfortunately, due to constrained work-site envelopes and limited numbers of restraint attachment locations, the monitor would probably be located outside this cone-of-vision. Thus, the crewmember would need to frequently turn his/her head to alternately view the task area and refer to the procedures and schematics displayed on the monitor. This increases task time and, more importantly, shakes the vestibular system. The latter often leads to "stomach awareness" and, consequently, reduced productivity.

However, if one "wore" the portable workstation, many of these obstacles could be overcome. There is clearly a need for modular, portable, "wearable" input and output devices. ${ }^{1}$ One such component would be a head-mounted display. This is not to be confused with a head-up display (requiring a visor) nor a helmet-mounted display (requiring a helmet), but a miniature monitor that can be worn on a lightweight headset. The "Private Eye" is such a device, and its evaluation is the subject of this report.

The Private Eye is a miniature monitor that, when placed before the eye, creates a virtual image equivalent to that seen on a 12 -in monitor 2 -ft away. The unit is 1.2 in (height) by 1.3 in (diameter) by 3.5 in (width), weighs $2.25 \mathrm{oz}$, and requires $1 / 3 \mathrm{~W}$ of power. Resolution is 720 horizontal by 280 vertical pixels with an image size of $21.8^{\circ}$ horizontal by $14.2^{\circ}$ vertical and refresh rate of $50 \mathrm{~Hz}$.

Two studies were conducted to assess the Private Eye's capabilities and limitations. The first examined the effects of different information presentation media (Private Eye, CRT, and hard copy) and work envelope volume (constrained and unconstrained) on the performance of an identification and manual assembly task. The second study, using the Private Eye as the presentation media, examined the effects of ambient illumination, luminous surfaces in the field-ofview, and background visual complexity on the performance of an interactive animated computer task. 


\section{EXPERIMENT 1}

\section{Method}

Overview. Subjects performed an identification and manual assembly task using visually presented component and configuration schematics. The task required the subject to frequently alternate attention between the displayed information and the task. Both work envelope volume and method of information presentation were manipulated.

Design. The experimental design used in this study was a 2 by 3 by 2 , full-factorial design with two within-subjects variables and one blocking variable (gender). Two independent variables were manipulated, the amount of physical space available to perform the task and the method by which the schematics were presented. The work envelope (WE) for the task had two levels: either constrained (within a simulated 19-in rack) or not constrained (on a table top). The presentation media (PM) for the graphical information had three levels: the Private Eye, a CRT monitor (RGB Apple II monitor), or hard copy (black graphics on white background on 8.5-by 11 -in sheets in landscape orientation). The presentation order of the six conditions was counter-balanced using a balanced latin square. Subjects were randomly assigned (without replacement) to one of the presentation sequences. Task and subtask times were collected as the dependent variables.

Subjects. Twelve NASA engineers (six males and six females) participated in this study on a voluntary basis.

Task. The task was to assemble the "Drive Ya Nuts" puzzle (Milton Bradley), consisting of seven "nuts" that must be placed on seven pegs. Each nut must be properly oriented and placed on the correct peg. Starting with the nuts upside-down, the subject would pick up and examine each until the correct one was identified, based upon the schematic of a nut presented on the display. Incorrect nuts were returned to the table upside-down. The display would then be advanced to the next schematic, showing where and in what orientation that nut should be placed. The subject would then place the nut accordingly. This continued until all seven nuts were in place. This task was chosen because it required frequent reference to the schematics to both identify the correct nut and place the nut on the correct peg in the proper orientation.

Materials and Apparatus. Six sets of schematics were developed for each of the presentation media (Private Eye, CRT, and hard copy). Each set consisted of seven pairs of identification schematics (fig. 1) and placement schematics (fig. 2) corresponding to the seven nuts and their associated locations. Each set began with an identification schematic of a nut that was to be located on one of the outer pegs, as indicated by the following placement schematic. The next two pairs of schematics were for nuts located on the nonadjacent outer pegs. The next three pairs completed the outer pegs with the seventh and final pair of schematics for the nut located in the center. Each set began with a different outer peg resulting in six sets. Subjects used each set once during a session, one for each experimental condition. The presentation order of the sets for each subject was counterbalanced using a balanced Latin square.

A "Fome-cor" box, with the front and back open, provided a "deep window" (12-in height by 9 -in diameter by 19 -in width) through which the subjects performed the task in the constrained WE condition. The intent was to simulate a maintenance and/or assembly task that might take place inside a 19-in wide rack (the rack size as currently baselined for S.S. Freedom). 


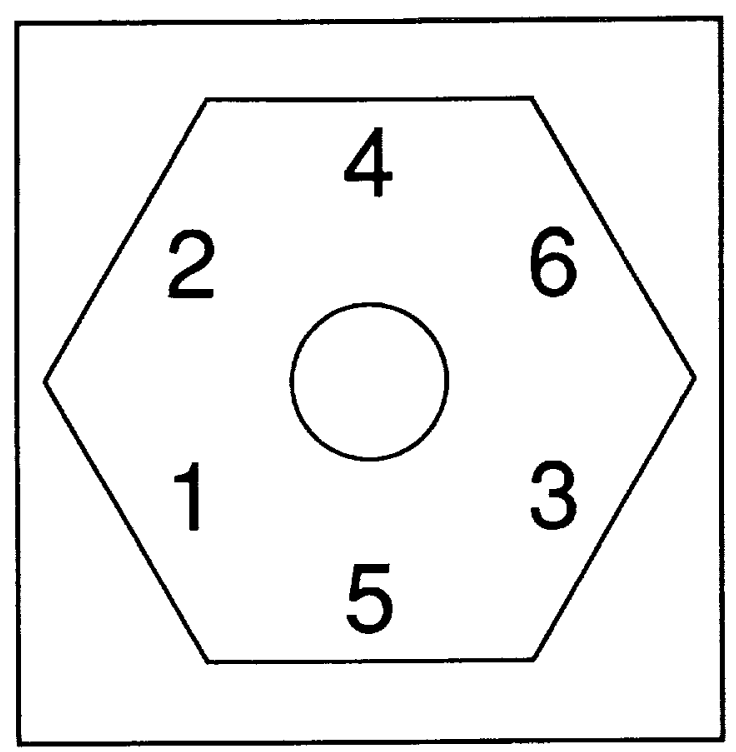

Figure 1. Identification schematic.

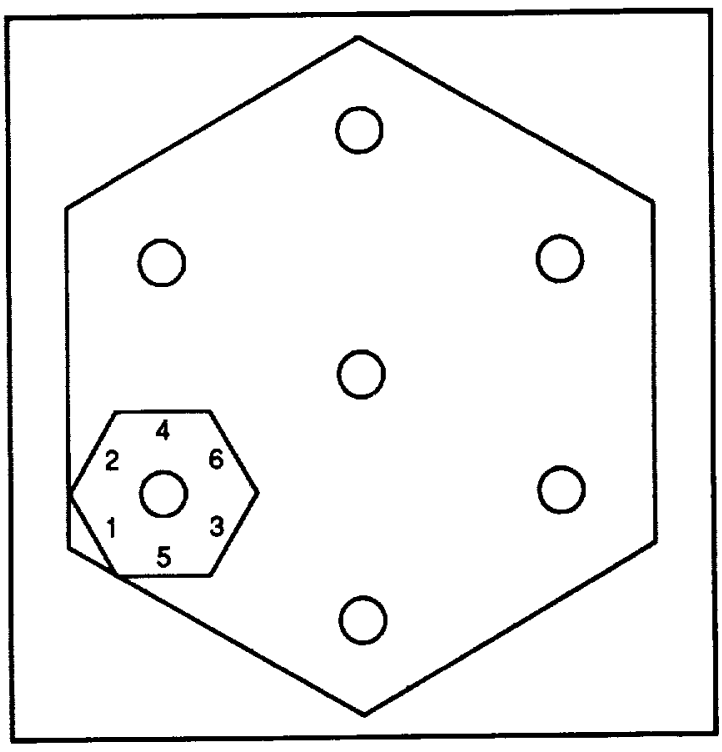

Figure 2. Placement schematic.

Procedure. Each subject would read a description of the experiment (appendix A), then read and sign an informed consent form (appendix B). Then following an acclimation period on the Private Eye and a short familiarization period on the puzzle, the experiment would begin. All six conditions were subsequently presented. There was a short rest period between trials while the equipment was reconfigured. The trial began as the subject "paged" to the first identification schematic. The initial identification subtask time began at this time and continued until the subject paged to the first placement schematic. The first placement subtask time then began and continued until the subject paged to the next identification schematic. This process was continued until the puzzle was completed. Upon completion of the final condition, the subjects were thanked and debriefed.

\section{Results}

The subtask times for the identification and placement of each nut were summed for each trial to give cumulative trial identification and placement task times. Analyses of variance were performed on these cumulative trial subtask times and on trial total task time. No significant main effects nor interactions were found in either total task times or identification times (tables 1 and 2).

The analysis of variance of the cumulative trial subtask placement times (table 3 ) showed a significant main effect of $\mathrm{PM}, F(2,20)=3.557, p<0.05$.

A post hoc Newman-Keuls pair-wise comparison of the means was performed at the 5-percent level of significance. Placement times were statistically significantly faster with the CRT than with the hard copy (table 4 and fig. 3 ), $\mathrm{CD}_{N-K}$ (first diagonal) $=5.49, \mathrm{CD}_{N-K}$ (second diagonal) $=$ 6.66. There were no other significant differences in this post hoc test.

A second set of analyses of variance was undertaken to ascertain whether or not there was any practice and/or fatigue effects occurring during the six "runs" within a session. These analyses included the Run*Gender interaction. A main effect of Run was found for the identification $\left(F^{*}(5,50)\right.$ $=2.446, p<0.05$, table 4), placement $(F(5,50)=8.860, p<0.001$, table 5), and total task times $(F(5,50)=5.578, p<0.001$, table 6). 
Table 1. Analysis of variance (ANOVA) summary table for total task times.

\begin{tabular}{|c|c|c|c|c|}
\hline Source & $d f$ & Sum of Squares & Mean Square & $\mathbf{F}$ \\
\hline $\begin{array}{c}\text { Between Subjects } \\
\text { Gender }(\mathrm{G}) \\
\text { Subjects }(\mathbf{S}) / \mathrm{G}\end{array}$ & $\begin{array}{r}1 \\
10\end{array}$ & $\begin{array}{r}6.125 \\
32,917.361\end{array}$ & $\begin{array}{r}6.125 \\
3,291.736\end{array}$ & 0.002 \\
\hline $\begin{array}{c}\text { Within Subjects } \\
\text { Presentation Media (PM) } \\
\mathrm{PM}^{*} \mathrm{G} \\
\mathrm{PM}^{*} \mathrm{~S} / \mathrm{G} \\
\text { Work Envelope (WE) } \\
\text { WE*G } \\
\mathrm{WE}^{*} \mathrm{~S} / \mathrm{G} \\
\mathrm{PM}^{*} \mathrm{WE} \\
\mathrm{PM}^{*} \mathrm{WE}^{*} \mathrm{G} \\
\mathrm{PM}^{*} \mathrm{WE}^{*} \mathrm{~S} / \mathrm{G}\end{array}$ & $\begin{array}{r}2 \\
2 \\
20 \\
1 \\
1 \\
10 \\
2 \\
2 \\
20\end{array}$ & $\begin{array}{r}356.778 \\
1,264.333 \\
10,136.556 \\
3,458.347 \\
572.347 \\
11,894.139 \\
1,480.778 \\
1,345.778 \\
14,497.111 \\
\end{array}$ & $\begin{array}{r}178.389 \\
632.167 \\
506.828 \\
3,458.347 \\
572.347 \\
1,189.414 \\
740.389 \\
672.889 \\
724.856 \\
\end{array}$ & $\begin{array}{l}0.352 \\
1.247 \\
\\
2.908 \\
0.481 \\
\\
1.021 \\
0.928\end{array}$ \\
\hline Total & 71 & $77,929.653$ & $11,973.487$ & \\
\hline
\end{tabular}

Table 2. ANOVA summary table for identification times.

\begin{tabular}{|c|c|c|c|c|}
\hline Source & $d f$ & Sum of Squares & Mean Square & $\mathbf{F}$ \\
\hline $\begin{array}{c}\text { Between Subjects } \\
\text { Gender (G) } \\
\text { Subjects (S)/G }\end{array}$ & $\begin{array}{r}1 \\
10\end{array}$ & $\begin{array}{r}171.125 \\
22,883.250\end{array}$ & $\begin{array}{r}171.125 \\
2,288.325\end{array}$ & 0.075 \\
\hline $\begin{array}{c}\text { Within Subjects } \\
\text { Presentation Media (PM) } \\
\text { PM*G } \\
\mathrm{PM}^{*} \mathrm{~S} / \mathrm{G} \\
\text { Work Envelope (WE) } \\
\text { WE*G } \\
\text { WE*S/G } \\
\mathrm{PM}^{*} \mathrm{WE} \\
\mathrm{PM}^{*} \mathrm{WE}^{*} \mathrm{G} \\
\mathrm{PM}^{*} \mathrm{WE}^{*} \mathrm{~S} / \mathrm{G} \\
\end{array}$ & $\begin{array}{r}2 \\
2 \\
20 \\
1 \\
1 \\
10 \\
2 \\
2 \\
20 \\
\end{array}$ & $\begin{array}{r}176.583 \\
1,383.083 \\
7,179.333 \\
1,711.125 \\
583.681 \\
5,249.028 \\
1,130.583 \\
859.194 \\
10,447.889 \\
\end{array}$ & $\begin{array}{r}88.292 \\
691.542 \\
358.967 \\
1,711.125 \\
583.681 \\
524.903 \\
565.292 \\
429.597 \\
522.394 \\
\end{array}$ & $\begin{array}{l}0.246 \\
1.926 \\
\\
3.260 \\
1.112 \\
\\
1.082 \\
0.822\end{array}$ \\
\hline Total & 71 & $51,774.874$ & $7,935.243$ & \\
\hline
\end{tabular}


Table 3. ANOVA summary table for placement times.

\begin{tabular}{|crccc|}
\hline Source & $d f$ & Sum of Squares & Mean Square & F \\
\hline Between Subjects & & & & \\
\hline Gender (G) & 1 & 112.500 & 112.500 & 0.396 \\
Subjects (S)/G & 10 & $2,837.611$ & 283.761 & \\
& & & & \\
Within Subjects & & & & \\
Presentation Media (PM) & 2 & 591.361 & 295.681 & $3.557 *$ \\
PM*G & 2 & 35.583 & 17.792 & 0.214 \\
PM$^{*}$ S/G & 20 & $1,662.389$ & 83.119 & \\
Work Envelope (WE) & 1 & 304.222 & 304.222 & 1.512 \\
WE*G & 1 & 0.056 & 0.056 & 0.000 \\
WE*S/G & 10 & $2,012.056$ & 201.206 & 0.138 \\
PM*WE & 2 & 25.861 & 12.931 & 0.502 \\
PM*WE*G $^{*}$ WE & 2 & 93.861 & 46.931 & \\
PM*WE*S/G & 20 & $1,870.944$ & 93.547 & \\
\hline Total & 71 & $9,546.444$ & $1,451.746$ & \\
${ }^{*} p=0.048$ & & & & \\
\hline
\end{tabular}

Table 4. Placement time as a function of presentation media.

\begin{tabular}{|cc|}
\hline Presentation Media & Mean $(s)$ \\
\hline CRT & 30.25 \\
Private Eye & 32.49 \\
Hard Copy & 37.13 \\
\hline
\end{tabular}

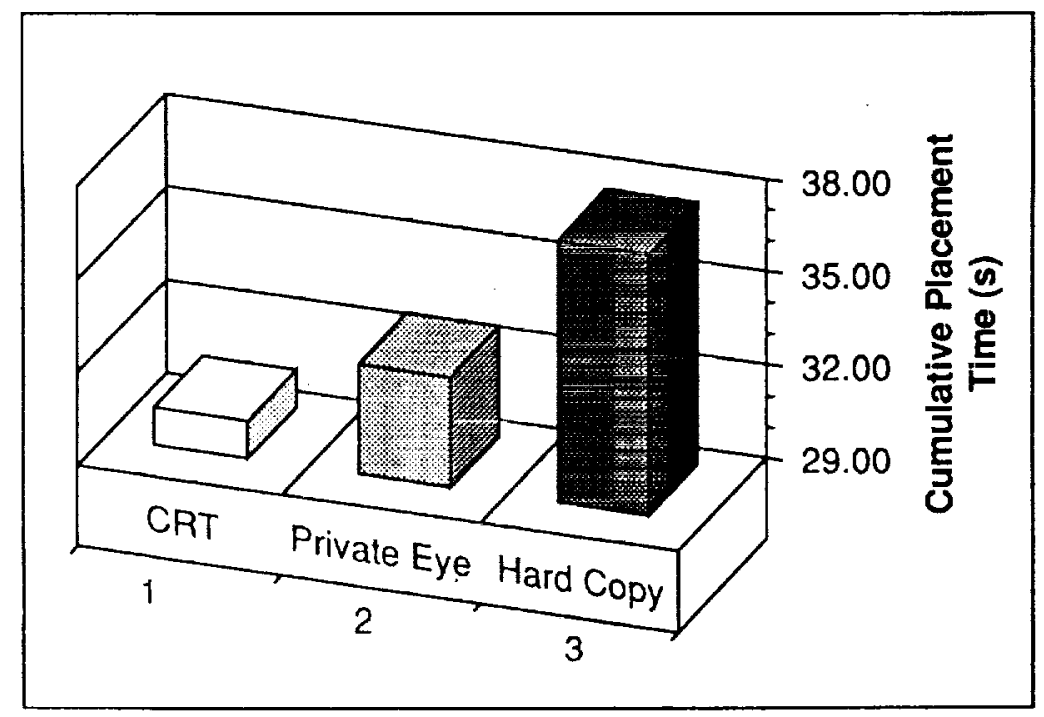

Figure 3. Cumulative placement time within trials as a function of presentation media. 
Table 5. ANOVA summary table for identification time.

\begin{tabular}{|crcrc|}
\hline Source & $d f$ & Sum of Squares & Mean Square & $\mathrm{F}$ \\
\hline Between Subjects & & & & \\
\hline Gender (G) & 1 & 171.125 & 171.125 & 0.075 \\
Subjects (S)/G & 10 & $22,883.250$ & $2,288.325$ & \\
& & & & \\
Within Subjects & & & & \\
Run (R) & 5 & $5,262.792$ & $1,052.558$ & $2.446 *$ \\
Run*G & 5 & $1,937.458$ & 387.492 & 0.900 \\
Run* $/ \mathrm{G}$ & 50 & $21,520.250$ & 430.405 & \\
\hline Total & 71 & $51,774.875$ & $4,329.905$ & \\
${ }_{p} p=0.0465$ & & & & \\
\hline
\end{tabular}

Table 6. ANOVA summary table for placement time.

\begin{tabular}{|crccc|}
\hline Source & $d f$ & Sum of Squares & Mean Square & F \\
\hline Between Subjects & & & & \\
\hline Gender (G) & 1 & 112.500 & 112.500 & 0.396 \\
Subjects (S)/G & 10 & $2,837.611$ & 283.761 & \\
& & & & \\
Within Subjects & & & & \\
\hline Run (R) & 5 & $2,789.778$ & 557.956 & 8.860 \\
Run*G & 5 & 657.833 & 131.567 & 2.089 \\
Run*S/G & 50 & $3,148.722$ & 62.974 & \\
\hline Total & 71 & $9,546.444$ & $1,148.758$ & \\
$*_{p=0.0001}^{*}$ * & & & & \\
\hline
\end{tabular}

Table 7. ANOVA summary table for total task time.

\begin{tabular}{|crccc|}
\hline Source & $d f$ & Sum of Squares & Mean Square & F \\
\hline Between Subjects & & & & \\
Gender (G) & 1 & 6.125 & 6.125 & 0.002 \\
Subjects (S)/G & 10 & $32,917.361$ & $3,291.736$ & \\
& & & & \\
Within Subjects & & & & \\
Run (R) & 5 & $15,191.236$ & $3,038.247$ & $5.578 *$ \\
Run*G & 5 & $27,578.792$ & 515.758 & 0.947 \\
Run*S/G & 50 & $27,236.139$ & 544.723 & \\
\hline Total & 71 & $77,929.653$ & $7,396.589$ & \\
${ }^{*} p=0.0004$ & & & & \\
\hline
\end{tabular}


Table 8. Identification time as a function of run number.

\begin{tabular}{|cc|}
\hline Run Number & Mean $(s)$ \\
\hline 1 & 86.9 \\
2 & 80.4 \\
3 & 66.7 \\
4 & 65.2 \\
5 & 68.8 \\
6 & 64.2 \\
\hline
\end{tabular}
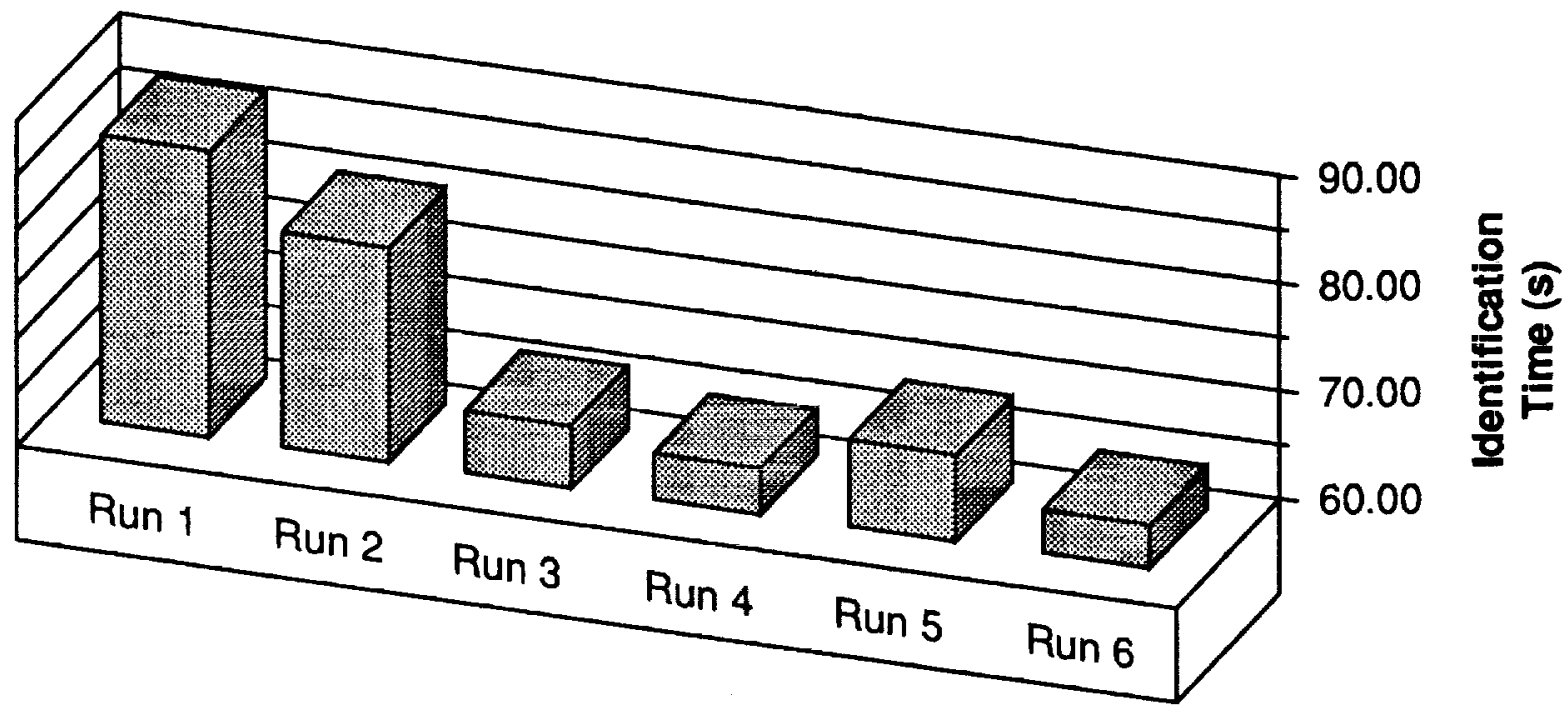

Figure 4. Identification time as a function of run number.

A post hoc Newman-Keuls pairwise comparison of the means was performed at the 5-percent level of significance for the main effect of Run for all three dependent variables.

There were five significantly different comparisons for placement times $\left(\mathrm{CD}_{N-K}\right.$ (first diagonal) $=6.517, \mathrm{CD}_{N-K}$ (second diagonal) $=7.834, \mathrm{CD}_{N-K}$ (third diagonal) $=8.625, \mathrm{CD}_{N-K}$ (fourth diagonal) $=9.186$, and $C D_{N-K}$ (fifth diagonal) $=9.609$ ). Placement times for the first run were significantly longer than for any of the five subsequent runs. No differences in placement time were found among the latter five runs (table 9 and fig. 5).

There were five significantly different comparisons for the total task times $\left(\mathrm{CD}_{N-K}\right.$ (first diagonal $)=19.168, \mathrm{CD}_{N-K}$ (second diagonal $)=23.041, \mathrm{CD}_{N-K}$ (third diagonal $)=25.365, \mathrm{CD}_{N-K}$ (fourth diagonal) $=27.016$, and $\mathrm{CD}_{N-K}$ (fifth diagonal) $=28.262$ ). Total task times for the first run were significantly longer than for any of the last four runs, but not significantly different from the second run. The second run was significantly longer than the fifth run. No differences in total task time were found among the latter four runs (table 10 and fig. 6). 
Table 9. Placement time as a function of run number.

\begin{tabular}{|cc|}
\hline Run Number & Mean $(s)$ \\
\hline 1 & 45.8 \\
2 & 36.0 \\
3 & 30.5 \\
4 & 31.3 \\
5 & 28.3 \\
6 & 27.7 \\
\hline
\end{tabular}

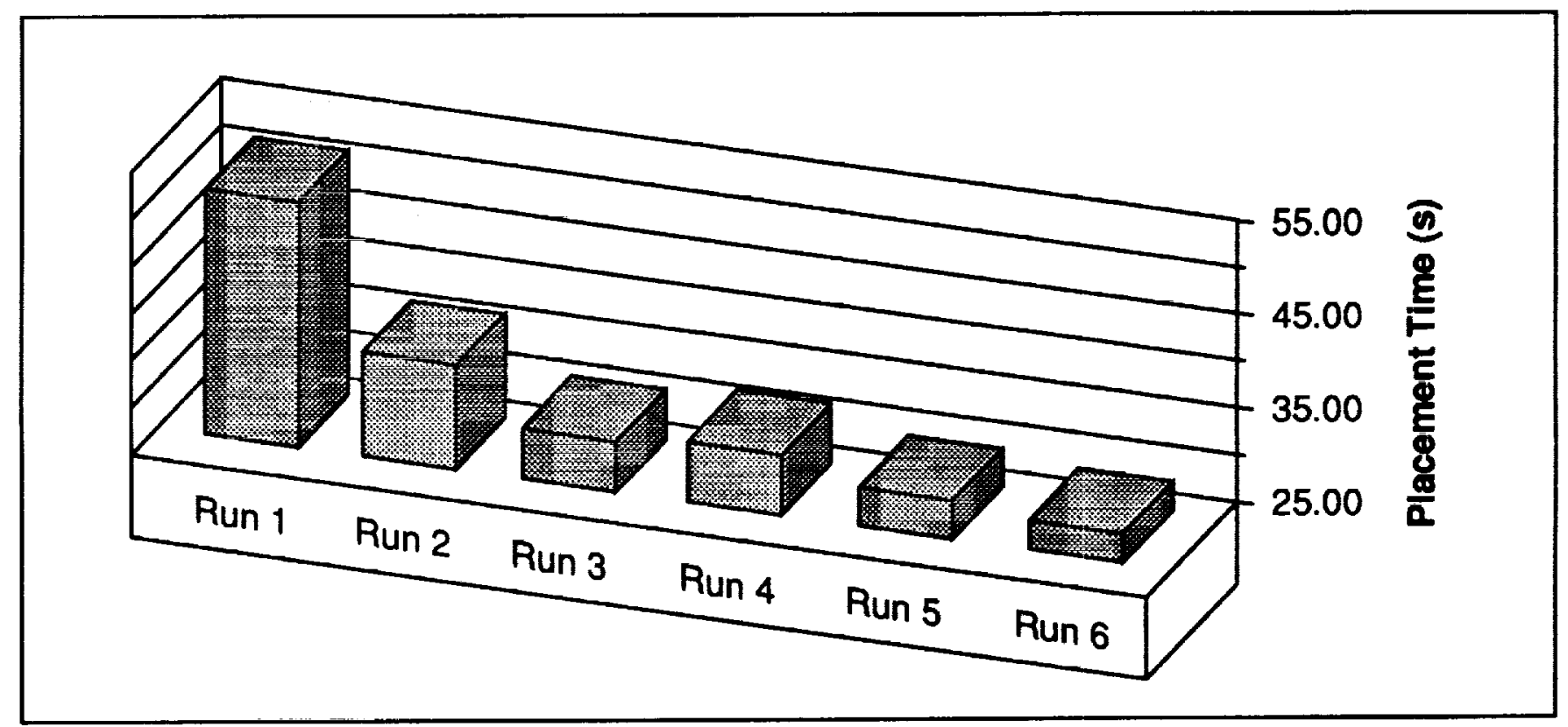

Figure 5. Placement time as a function of run number.

Table 10. Total task time as a function of run number.

\begin{tabular}{|cc|}
\hline Run Number & Mean $(s)$ \\
\hline 1 & 132.7 \\
2 & 116.4 \\
3 & 97.2 \\
4 & 96.5 \\
5 & 97.2 \\
6 & 91.9 \\
\hline
\end{tabular}




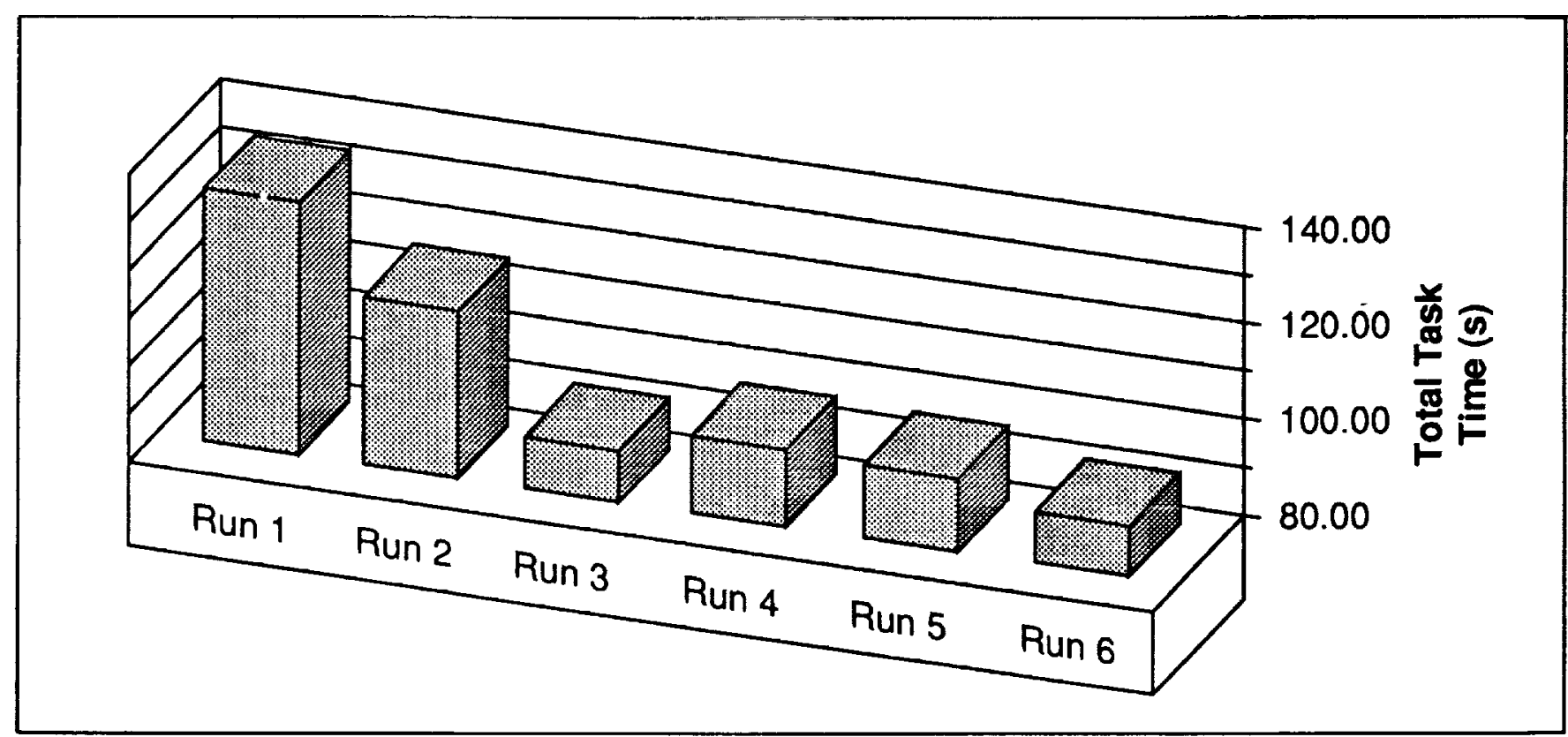

Figure 6. Total task time as a function of run number.

No statistically significant differences were noted among the runs in identification times using the Newman-Keuls test $\left(\mathrm{CD}_{N-K}\right.$ (first diagonal $)=17.038, \mathrm{CD}_{N-K}$ (second diagonal $)=20.481, \mathrm{CD}_{N-K}$ $($ third diagonal $)=22.547, \mathrm{CD}_{N-K}($ fourth diagonal $)=24.014$, and $\mathrm{CD}_{N-K}($ fifth diagonal $\left.)=25.122\right)$.

However, since the ANOVA $F$-ratio for this main effect was statistically significant, further analysis was indicated to uncover the basis for this finding. Thus, a less conservative least significant difference (LSD) test, still at the 5-percent level of significance, was performed. Four comparisons were significant using this test $\left(\mathrm{CD}_{L S D}=17.024\right)$. Identification times for the first run were significantly longer than for any of the last four runs, but not significantly different from the second run. No differences in identification time were found among the latter five runs (table 8 and fig. 4).

\section{Discussion}

There were two related goals in the first experiment. The first was to determine if the Private Eye was suitable for a task that required frequent reference to displayed information. That is, would it compare favorably with more "standard" methods of information presentation (e.g., CRT and hard copy)? The second goal was to compare the three media in a constrained work environment, one that should clearly favor ready access to the necessary displayed information.

In terms of the first goal, the Private Eye compares quite favorably with both the CRT and hard copy. No decrements in performance were evident with the Private Eye, vis-a-vis, the CRT and hard copy. The only difference in this area was between the CRT and hard copy, which is more than likely an artifact of the "paging" method (i.e., a keystroke for the CRT versus manually flipping a page for the hard copy).

The second goal was not fully demonstrated. The task design, in all fairness, could not place the CRT and hard copy so far away as to require the subject to physically move to access the information. Adding transit lime to the subtask times would have clearly biased the results in favor of the Private Eye. The decision was made to place the CRT and hard copy in the optimal position in each 
case. That is, as close as possible to the edge of the constrained work envelope. Initial consideration would seem to indicate that when this is possible there is no clear advantage (or disadvantage) in using the Private Eye. However, applications where it is possible to optimally position the monitor or hard copy may be infrequent, particularly if the application is similar to an in situ maintenance task.

Another finding in this experiment relates to a training or practice effect. Placement times were longer in the first run than the following runs. Using a less conservative test, a similar trend was found for identification times. Combined total task times also showed this improvement in performance. In general, improvement was evident following the first and, to some extent, the second runs. By the third run, this improvement had leveled off. The most likely explanation for this finding is a practice effect, both with the task and the experiment. That is, the subject becomes better at the task and more relaxed during the experiment. More practice is indicated in the former and may even help to alleviate the latter.

As with all within-subject's experiments, one must anticipate carry-over effects from one condition to another and design accordingly. In this experiment, a balanced Latin square was employed to counterbalance the sequences of condition presentation. With this technique, each condition precedes and follows every other condition an equal number of times, thus carry-over effects and differential transfer effects are decoupled from the independent variables of interest.

Further consideration for applications within a microgravity environment argues well for use of the Private Eye. Even in the best case, where a standard-sized monitor or hard copy could be placed at the edge of the constrained work envelope, the user would be required to frequently turn his/her head to alternately view the task and the displayed information.

As noted above, this raises havoc within the otolith organs, causing the otoliths to "slosh" around inside the utricle and saccule, the organs that sense gravity and linear accelerations of the head. ${ }^{2}$ In a one-gravity environment, this is not a problem since gravity is an overwhelming acceleration force, holding the otoliths rather stable. In orbit, however, one is in a continual free-fall, free of the effects of Earth's gravity. There, head movements shake the otolith organs causing uncomfortable sensations (e.g., stomach awareness, etc.).

The task design could not satisfactorily reproduce these effects of frequent head movement in a microgravity environment, hence the presumed superiority of the Private Eye in this application was not adequately, empirically addressed. In theory, though, the Private Eye should prove superior in this type of environment. A Spacelab flight test should be arranged to verify this empirically.

\section{EXPERIMENT 2}

\section{Method}

Overview. Subjects "played" an interactive video game using the Private Eye as a monitor. The task required close, focused attention on the monitor. Ambient illumination, background visual complexity, and luminous surfaces within the visual field were manipulated.

Design. The experimental design used in this study was a $2^{4}$, full-factorial design with three within-subjects variables and one blocking variable (Gender). Three two-level independent variables were manipulated: the amount of ambient illumination (AI) in the experiment room 
(bright/dark), the degree of visual complexity (background visual complexity (BVC)) of the wall the subject faced (simple/complex), and luminous surfaces (LS) within the subject's visual field (present/absent). Presentation order of the eight conditions were counter-balanced using a balanced Latin square. Subjects were randomly assigned (without placement) to one of the presentation sequences. Game scores were recorded as the dependent variable.

Subjects. Sixteen NASA and contractor engineers (eight males and eight females) participated in this study on a voluntary basis.

Task. The task used in this study was "Space Invaders," an interactive, animated video game. The objective of the game was to "shoot space invaders" with missiles from "rocket ships." The invaders were arranged in a 5 by 9 matrix that slowly advanced towards the bottom of the screen. The subject controlled the motion of the ship using the cursor movement keys and fired missiles using the space key. The invaders also fired missiles that could destroy the ship. The subject began with three ships in each game. A game ended when all three ships were destroyed. Each subject played five games per condition. The dependent variable was the game score.

A task was needed that required constant, focused attention. In the "real world" application, the user will be highly motivated to attend to the displayed information. In the laboratory environment, however, instructing a subject to be motivated does not necessarily result in a motivated subject. By choosing a simple game, it was assumed that the subjects were motivated by a sense of competition and, therefore, focused their attention on the task. The interactive nature of the task ensured constant attention and further enhanced focused attention.

Materials and Apparatus. Subjects sat in an American Ergonomics' "Ergomax" chair at a 3-ft wide "computer" table with a keyboard located directly in front of them. The small experiment room (4-ft wide by 10-ft long) was illuminated by an overhead, indirect fluorescent lighting system for the bright ambient illumination conditions. This lighting system was turned off in the "dark" ambient illumination conditions.

Two sheets of "Fome-cor" provided the two BVC stimuli. One was painted flat black (4.3percent reflectance), providing a visually simple background. The other was white with 2 -in wide horizontal and vertical strips of black tape placed at 4 -in centers across the surface, resulting in 2 -in white squares (85.8-percent reflectance) surrounded by 2 -in wide horizontal and vertical black stripes (3.0-percent reflectance). This provided the visually complex background with an overall reflectance of 44.4 percent. These sheets were placed, in turn, on top of and perpendicular to the table top, 9 in from the front edge.

A Sunnex 700 series halogen task lamp was placed behind and to the right of the subject. Its 3,000 to $3,200 \mathrm{~K}$ light was directed onto the surface of the Private Eye assembly, to the right of the display, to provide the luminous surface (i.e., glare) in the subject's visual field condition.

Illumination values were determined for the various lighting conditions. Placing the photometer sensor adjacent to the right eye reference position (ERP), readings were taken with the sensor pointing up, in (toward the BVC stimulus panels), and to the right side for each of the eight treatment conditions (table 11). 
Table 11. Illumination values for experimental conditions.*

\begin{tabular}{|c|c|c|c|c|c|c|}
\hline \multirow{2}{*}{\multicolumn{3}{|c|}{$\frac{\text { Luminous Surfaces }}{\text { Ambient Illumination }}$}} & \multicolumn{2}{|c|}{ Glare } & \multicolumn{2}{|c|}{ No Glare } \\
\hline & & & Bright & Dark & Bright & Dark \\
\hline & & Direction & & & & \\
\hline \multirow{2}{*}{$\begin{array}{l}\text { Background } \\
\text { Visual } \\
\text { Complexity }\end{array}$} & Complex & $\begin{array}{c}\text { Up } \\
\text { In } \\
\text { Side }\end{array}$ & $\begin{array}{l}89.0 \\
23.5 \\
40.2\end{array}$ & $\begin{array}{r}11.0 \\
2.8 \\
7.0\end{array}$ & $\begin{array}{l}86.5 \\
21.0 \\
33.0\end{array}$ & $\begin{array}{l}\text { Negligible } \\
\text { Negligible } \\
\text { Negligible }\end{array}$ \\
\hline & Simple & $\begin{array}{c}\text { Up } \\
\text { In } \\
\text { Side }\end{array}$ & $\begin{array}{l}75.0 \\
13.5 \\
36.0\end{array}$ & $\begin{array}{l}4.6 \\
0.8 \\
6.0\end{array}$ & $\begin{array}{l}67.5 \\
12.7 \\
30.0\end{array}$ & $\begin{array}{l}\text { Negligible } \\
\text { Negligible } \\
\text { Negligible }\end{array}$ \\
\hline
\end{tabular}

Procedure. Prior to the day of the test sessions, each subject participated in a practice session. This was to both practice playing "Space Invaders" and to become familiar and comfortable with the Private Eye. Subjective self-report was the end-of-practice criterion.

Prior to the test session, each subject would read a description of the experiment (appendix C), then read and sign an informed consent form (appendix B). Then, following a short "warm-up" and acclimation period on the task and the Private Eye, the experiment would begin. All eight conditions were subsequently presented. There was a short rest period between trials while the equipment was reconfigured. Upon completion of the final condition, subjects completed a short questionnaire (appendix D), then were debriefed and thanked for their participation.

\section{Results}

The five game scores within each condition were averaged to give a mean score for each subject for each condition. An analysis of variance was performed on these means scores (table 12). This analysis showed a significant main effect of LS's within the visual field. Direct glare had a statistically significant detrimental effect on performance, $F(1,14)=5.715, p<0.05$ (table 13 and fig. 7).

There were two statistically significant interaction effects on performance, AI by LS by G, $F(1,14)=9.700, p<0.01$ (table 8 and fig. 5 ), and AI by BVC by G, $F(1,14)=5.524$, $p<0.05$ (table 15 and fig. 9).

A post hoc Newman-Keuls pair-wise comparison of the means was performed at the 5-percent level of significance for each interaction. There were six significantly different comparisons in the AI by $L S$ by $G$ interaction $\left(C D_{N-K}\right.$ (first diagonal $)=219.7, C_{N-K}$ (second diagonal $)=268.3, C_{N-K}$ (third diagonal $)=298.0, \mathrm{CD}_{N-K}$ (fourth diagonal $)=319.7, \mathrm{CD}_{N-K}$ (fifth diagonal) $=336.4, \mathrm{CD}_{N-K}$ (sixth diagonal) $=350.2$, and $\mathrm{CD}_{N-K}($ seventh diagonal $\left.)=361.8\right)$. 
Table 12. ANOVA summary table for mean scores.

\begin{tabular}{|c|c|c|c|c|}
\hline Source & $d f$ & Sum of Squares & Mean Square & $\mathbf{F}$ \\
\hline \multicolumn{5}{|l|}{ Between Subjects } \\
\hline Gender (G) & 1 & $232,988.445$ & $232,988.445$ & 0.272 \\
\hline Subjects $(\mathbf{S}) / \mathrm{G}$ & 14 & $11,997.665$ & $856,976.048$ & \\
\hline \multicolumn{5}{|l|}{ Within Subjects } \\
\hline $\begin{array}{l}\text { Ambient Illumination } \\
\text { (AI) }\end{array}$ & 1 & $13,633.133$ & $13,633.133$ & 0.095 \\
\hline $\mathrm{AI}^{*} \mathrm{G}$ & 1 & 273.195 & 273.195 & 0.002 \\
\hline$A I^{*} S / G$ & 14 & $2,012,216.297$ & $143,729.735$ & \\
\hline $\begin{array}{c}\text { Luminous Surfaces } \\
\text { (LS) }\end{array}$ & 1 & $1,567,556.445$ & $1,567,556.445$ & $5.715 *$ \\
\hline $\mathrm{LS} * \mathrm{G}$ & 1 & $426,541.570$ & $426,541.570$ & 1.555 \\
\hline $\mathbf{L S} * \mathbf{S} / \mathrm{G}$ & 14 & $3,839,777.109$ & $274,269.794$ & \\
\hline Background Visual & 1 & $62,613.758$ & $62,613.758$ & 0.797 \\
\hline \multicolumn{5}{|l|}{ Complexity (BVC) } \\
\hline $\mathrm{BVC}^{*} \mathrm{G}$ & 1 & $4,429.658$ & $4,429.758$ & 0.056 \\
\hline$B V C^{*} S / G$ & 14 & $1,099,762.609$ & $78,554.472$ & \\
\hline$A I^{*} \overline{L S}$ & 1 & $33,120.945$ & $33,120.945$ & 0.394 \\
\hline$A I^{*} L S * G$ & 1 & $815,843.445$ & $815,843.445$ & $9.700^{\dagger}$ \\
\hline $\mathrm{AI}^{*} \mathrm{LS}^{*} \mathrm{~S} / \mathrm{G}$ & 14 & $1,177,477.734$ & $84,105.552$ & \\
\hline $\mathrm{AI} \mathrm{I}^{*} \mathrm{BC}$ & 1 & $183,542.258$ & $183,542.258$ & 1.002 \\
\hline$A I^{*} B V C * G$ & 1 & $1,012,286.633$ & $1,012,286.633$ & $5.524^{\ddagger}$ \\
\hline$A I * B V C * S / G$ & 14 & $2,565,496.234$ & $183,249.731$ & \\
\hline LS*BVC & 1 & $166,536.633$ & $166,536.633$ & 0.975 \\
\hline $\mathrm{LS}^{*} \mathrm{BVC} \mathrm{C}^{*} \mathrm{G}$ & 1 & $116,825.695$ & $116,825.695$ & 0.684 \\
\hline $\mathrm{LS} \mathrm{BVC}^{*} \mathrm{~S} / \mathrm{G}$ & 14 & $2,391,073.297$ & $170,790.950$ & \\
\hline $\mathrm{AI}{ }^{*} \mathrm{LS} * \mathrm{BVC}$ & 1 & $252,849.383$ & $252,849.383$ & 0.714 \\
\hline $\mathrm{AI}^{*} \mathrm{LS}^{*} \mathrm{BVC}^{*} \mathrm{G}$ & 1 & $795,848.820$ & $795,848.820$ & 2.248 \\
\hline$A I^{*} L S * B V C * S / G$ & 14 & $4,956,829.422$ & $354,059.244$ & \\
\hline Total & 127 & $35,725,187.818$ & $7,830,625.642$ & \\
\hline${ }^{*} p=0.031$ & & & & \\
\hline$p=0.008$ & & & & \\
\hline$p=0.034$ & & & & \\
\hline
\end{tabular}


Table 13. Mean score as a function of luminous surfaces.

\begin{tabular}{|c|c|}
\hline Luminous Surfaces & Mean Score \\
\hline No Glare & $2,112.9$ \\
Glare & $1,891.6$ \\
\hline
\end{tabular}

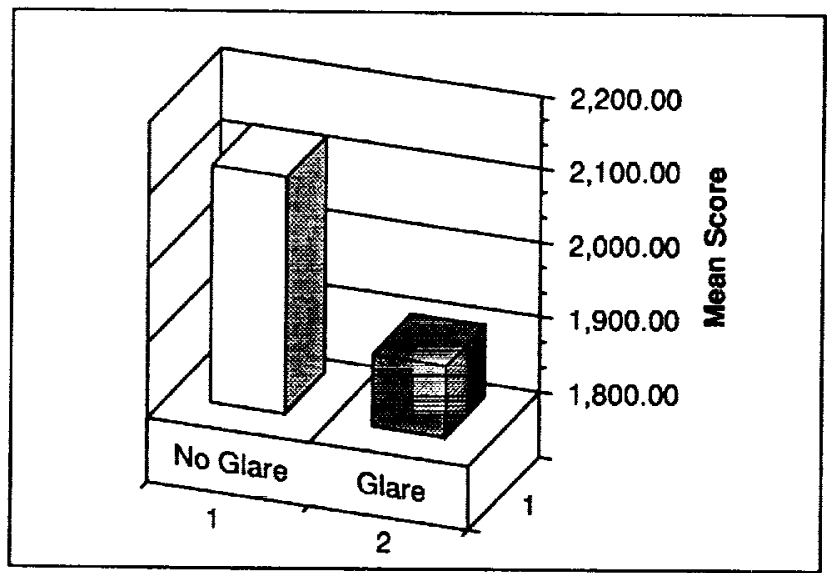

Figure 7. Mean score as a function of LS's in the visual field.

Table 14. Mean score as a function of AI, LS, and G.

\begin{tabular}{|c|c|c|c|}
\hline \multirow{2}{*}{$\begin{array}{l}\text { Luminoous } \\
\text { Surfaces }\end{array}$} & \multirow{2}{*}{$\begin{array}{l}\text { Ambient } \\
\text { Illumination }\end{array}$} & \multicolumn{2}{|c|}{ Gender } \\
\hline & & Male & Female \\
\hline No Glare & $\begin{array}{l}\text { Dark } \\
\text { Bright }\end{array}$ & $\begin{array}{l}2,232.8 \\
2,023.2\end{array}$ & $\begin{array}{l}2,045.9 \\
2,149.8\end{array}$ \\
\hline Glare & $\begin{array}{l}\text { Dark } \\
\text { Bright }\end{array}$ & $\begin{array}{l}1,704.1 \\
1,878.2\end{array}$ & $\begin{array}{l}2,067.5 \\
1,916.4\end{array}$ \\
\hline
\end{tabular}

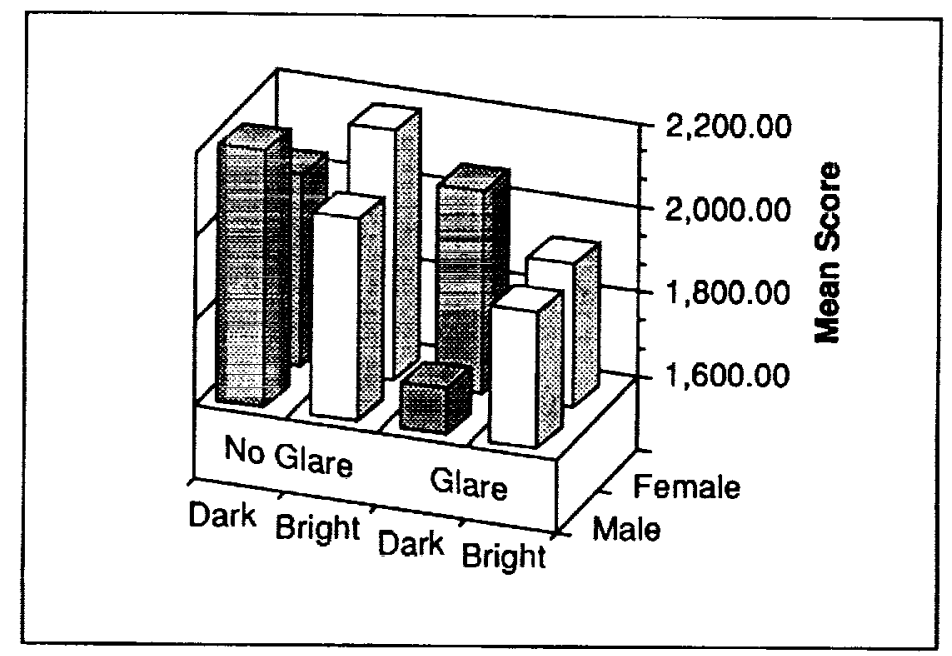

Figure 8. Mean score as a function of AI, LS's in the visual field, and G. 
Table 15. Mean score as a function of AI, BVC, and G.

\begin{tabular}{|c|c|c|c|}
\hline \multirow{2}{*}{$\begin{array}{c}\text { Background } \\
\text { Visual Complexity }\end{array}$} & \multirow{2}{*}{$\begin{array}{c}\text { Ambient } \\
\text { Ilumination }\end{array}$} & \multicolumn{2}{|c|}{ Gender } \\
\cline { 3 - 4 } Simple & Dark & $1,857.9$ & Female \\
& Bright & $2,093.8$ & $2,135.8$ \\
& Dark & $2,079.0$ & $1,977.6$ \\
\hline \multirow{2}{*}{ Complex } & Bright & $1,807.7$ & $2,056.2$ \\
& &
\end{tabular}

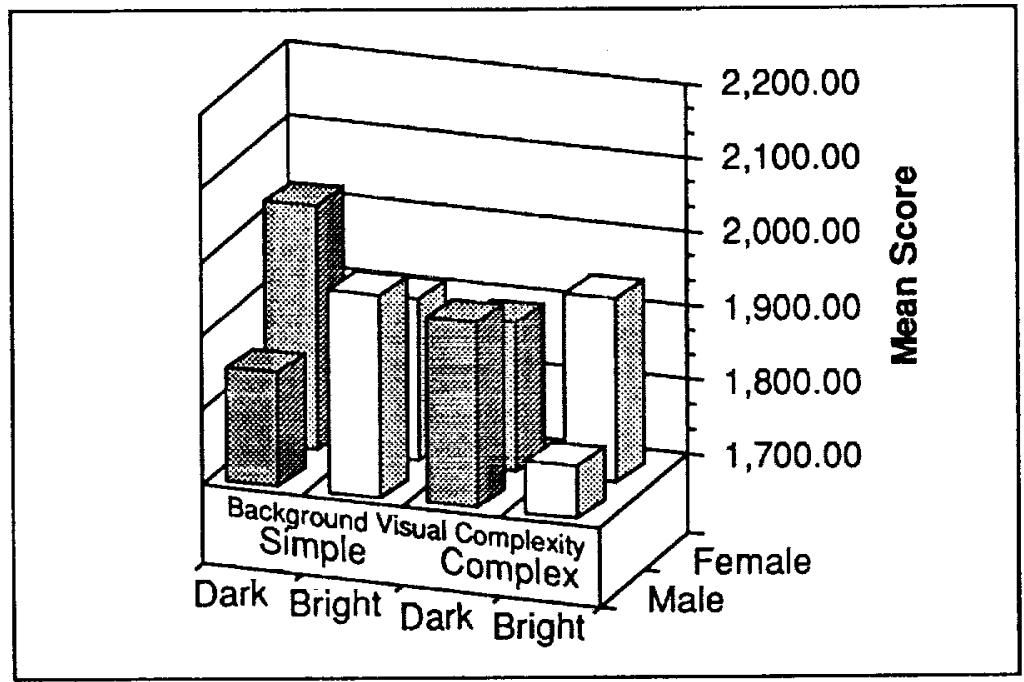

Figure 9. Mean score as a function of AI, BVC, and G.

In the dark condition with glare, females scored more points than males. Without glare, in both bright and dark conditions, males and females scored more points than did males in the dark condition with glare. Finally, males scored more points in the dark without glare than they did in the bright condition with glare.

No statistically significant differences were noted in the AI by BVC by $\mathrm{G}$ interaction using the Newman-Keuls test $\left(\mathrm{CD}_{N-K}\right.$ (first diagonal) $=324.3, \mathrm{CD}_{N-K}$ (second diagonal) $=328.6, \mathrm{CD}_{N-K}$ (third diagonal) $=439.8, \mathrm{CD}_{N-K}$ (fourth diagonal $)=471.9, \mathrm{CD}_{N-K}$ (fifth diagonal) $=496.6, \mathrm{CD}_{N-K}$ $($ sixth diagonal $)=516.9$, and $\mathrm{CD}_{N-K}$ (seventh diagonal $)=534.0$ ).

However, since the ANOVA $F$-ratio for this interaction was statistically significant, further analysis was indicated to uncover the basis for this finding. Thus, a less conservative LSD test, still in the 5-percent level of significance, was performed. One comparison was significant using this test $\left(C D_{L S D}=324.6\right)$. Females, in the dark with a simple visual background, scored more points than did males in the bright ambient condition with a complex visual background.

A second set of analyses of variance was undertaken to ascertain whether or not there was any practice and/or fatigue effects occurring during the five "games" within a trial and/or the eight "trials" within a session. These analyses included the Game*Gender and Trial*Gender interactions. There were no statistically significant main effects nor interactions found in this analysis (table 16). 
Table 16. ANOVA summary table for score.

\begin{tabular}{|crrrr|}
\hline Source & $d f$ & Sum of Squares & Mean Square & F \\
\hline Between Subjects & & & & \\
\hline Gender (G) & 1 & $1,208,014.814$ & $1,208,014.814$ & 0.280 \\
Subjects (S)/G & 14 & $60,302,285.341$ & $4,307,306.096$ & \\
& & & & \\
Within Subjects & & & & \\
Trial (T) & 7 & $7,285,353.027$ & $1,040,764.718$ & 0.988 \\
T*G & 7 & $7,158,430.281$ & $1,022,632.897$ & 0.971 \\
$T^{*} \mathrm{~S} / \mathrm{G}$ & 98 & $103,221,844.223$ & $1,053.284 .125$ & \\
Game & 4 & $5,737,800.056$ & $1,434,450.014$ & 1.464 \\
Game*G & 4 & $3,855,357.745$ & $963,839.436$ & 0.984 \\
Game* $e^{*} / G$ & 56 & $54,872,180.431$ & $979,860.365$ & \\
Residual & 448 & $352,082,597.986$ & $785,898.656$ & \\
\hline Total & 639 & $595,723,863.904$ & $12,796,051.121$ & \\
\hline
\end{tabular}

Table 17. Descriptive statistics for the questionnaire.

\begin{tabular}{|c|c|}
\hline Question & Response* \\
\hline $\begin{array}{l}\text { Frequency of playing video games } \\
\text { Ever played "Space Invaders"* } \\
\text { Adequacy of PE as compared to a CRT } \\
\text { Dominant eye } \\
\text { Difficulty in focusing on Private Eye } \\
\text { Level of comfort } \\
\text { Wear glasses/contacts } \\
\text { More comfortable light level } \\
\text { Distraction of direct task light } \\
\text { Distraction of background walls } \\
\text { Difficulty at blocking out distractions } \\
\text { Fatigue level at completion } \\
\text { Overall impression of the Private Eye } \\
\text { Adequate training period" } \\
\text { Current emotional/physical condition }\end{array}$ & $\begin{array}{c}1 \\
\text { Yes }=7 / \mathrm{No}=4 \\
4 \\
\text { Left }=2 / \text { Right }=14 \\
3 \\
3 \\
\text { Yes }=7 / \text { No }=9 \\
\text { High }=5 / \text { Low }=11 \\
4 \\
3 \\
2 \\
3 \\
4 \\
\text { Yes } \\
4\end{array}$ \\
\hline \multicolumn{2}{|c|}{$\begin{array}{l}\text { *Rounded mean responses are } 1=\text { low } / 5=\text { high, except as noted } \\
+0=\text { none } / 5=\text { high } \\
{ }^{*} \text { No response from five subjects } \\
\text { 'All subjects responded yes }\end{array}$} \\
\hline
\end{tabular}

Responses to the questionnaire were reduced and coded. Questions 1 and 2 were combined into one six-point question. The rest of the questions remained as written. Means or frequencies were computed for these questions (table 17). 
Correlation coefficients were computed among selected questions concerning adequacy of the Private Eye as compared with a CRT, a subject's dominant eye, difficulty in focusing, level of comfort, and whether or not a subject wore glasses or contacts (table 18). Notable findings include a relatively high correlation between perceived adequacy of the Private Eye (relative to a "normal monitor") and reported level of comfort $\left(R=0.741, R^{2}=0.548\right)$. Moderate correlations were found between perceived adequacy of the Private Eye and a dominant right eye $\left(R=0.562, R^{2}=0.316\right)$, reported level of comfort and a dominant right eye $\left(R=0.493, R^{2}=0.243\right)$, and reported level of comfort and the use of glasses or contacts $\left(R=0.572, R^{2}=0.327\right)$. Little or no correlation was found between difficulty in focusing and perceived adequacy of the Private Eye $\left(R=0.081, R^{2}=0.007\right)$, a dominant right eye $\left(R=0.249, R^{2}=0.062\right)$, level of comfort $\left(R=0.066, R^{2}=0.004\right)$, or use of glasses or contacts $\left(R=0.143, R^{2}=0.021\right)$ and between perceived adequacy of the Private Eye and the use of glasses or contacts $\left(R=0.372, R^{2}=0.138\right)$.

Table 18. Correlations among selected questions.*

\begin{tabular}{|c|c|c|c|c|c|}
\hline Question & $\begin{array}{l}\text { PE vs. } \\
\text { CRT }\end{array}$ & $\begin{array}{l}\text { Dominant } \\
\text { Eye }\end{array}$ & $\begin{array}{l}\text { Difficulty in } \\
\text { Focusing }\end{array}$ & $\begin{array}{l}\text { Level of } \\
\text { Comfort }\end{array}$ & $\begin{array}{l}\text { Glasses/ } \\
\text { Contacts }\end{array}$ \\
\hline $\begin{array}{l}\text { PE vs. CRT } \\
\text { Dominant eye } \\
\text { Difficulty in fo } \\
\text { Level of comfo } \\
\text { Glasses/contac }\end{array}$ & $\mathrm{x}$ & $\begin{array}{c}0.56210 .316 \\
x\end{array}$ & $\begin{array}{c}0.081 / 0.007 \\
0.249 / 0.062 \\
X\end{array}$ & $\begin{array}{c}0.741 / 0.548 \\
0.493 / 0.243 \\
0.066 / 0.004 \\
X\end{array}$ & $\begin{array}{c}0.3720 .138 \\
N / A \\
0.143 / A .021 \\
0.5720 .327 \\
X\end{array}$ \\
\hline
\end{tabular}

Correlations between perceived distractions and reported fatigue level at the completion of the session were computed (table 19). Notably, there was little correlation between reported fatigue and the perceived distractions of the task light $\left(R=0.160, R^{2}=0.026\right)$ or the background walls $\left(R=0.129, R^{2}=0.017\right)$, but a relatively large correlation between reported fatigue and the reported difficulty in blocking out distractions $\left(R=0.803, R^{2}=0.645\right)$.

Table 19. Correlations between perceived distractions and reported fatigue.*

\begin{tabular}{|ll|}
\hline \multicolumn{1}{|c|}{ Question } & $\begin{array}{c}\text { Fatigue level } \\
\text { at completion }\end{array}$ \\
\hline Distraction of direct task light & $0.160 / 0.026$ \\
Distraction of background walls & $0.129 / 0.017$ \\
Difficulty at blocking out distractions & $0.803 / 0.645$ \\
\hline *R/R & \\
\hline
\end{tabular}

There were few notable correlations between gender and selected questions (table 20). Low to moderate correlations were found between being female and perceived adequacy of the Private Eye $\left(R=0.557, R^{2}=0.310\right)$, level of comfort $\left(R=0.365, R^{2}=0.134\right)$, and positive emotional and/or physical condition $\left(R=0.354, R^{2}=0.126\right)$. Little or no correlation was found between gender and frequency of playing video games $\left(R=0.113, R^{2}=0.013\right)$, difficulty in focusing $(R=0.180$, $\left.R^{2}=0.032\right)$, distraction of direct task light $\left(R=0.146, R^{2}=0.021\right)$ or background walls $(R=0.095$, $\left.R^{2}=0.009\right)$, difficulty at blocking out distractions $\left(R=0.103, R^{2}=0.011\right)$, fatigue level $(R=0.194$, $\left.R^{2}=0.038\right)$, or overall impression of the Private Eye $\left(R=0.222, R^{2}=0.049\right)$. 
Table 20. Correlations between gender and selected questions.*

\begin{tabular}{|lc|}
\hline \multicolumn{1}{|c|}{ Question } & Gender \\
\hline Frequency of playing video games & $0.113 / 0.013$ \\
Adequacy of PE as compared to a CRT & $0.557 / 0.310$ \\
Difficulty in focusing on Private Eye & $0.180 / 0.032$ \\
Level of comfort & $0.365 / 0.134$ \\
Distraction of direct task light & $0.146 / 0.021$ \\
Distraction of background walls & $0.095 / 0.009$ \\
Difficulty at blocking out distractions & $0.103 / 0.011$ \\
Fatigue level at completion & $0.194 / 0.038$ \\
Overall impression of the Private Eye & $0.222 / 0.049$ \\
Current emotional/physical condition & $0.354 / 0.126$ \\
\hline$* \mathrm{R} / \mathrm{R}^{2}$ & \\
\hline
\end{tabular}

Finally, correlations between the session mean score and the questionnaire responses were computed (table 21). Low to moderate correlations were found between session mean scores and frequency of playing video games $\left(R=0.445, R^{2}=0.198\right)$, a dominant right eye $(R=0.419$, $\left.R^{2}=0.176\right)$, and difficulty in focusing $\left(R=0.465, R^{2}=0.216\right)$. Little or no correlation was found between session mean scores and having ever played "Space Invaders" $\left(R=0.224, R^{2}=0.050\right)$, perceived adequacy of the Private Eye $\left(R=0.059, R^{2}=0.003\right)$, level of comfort $(R=0.076$, $\left.R^{2}=0.006\right)$, the use of glasses or contacts $\left(R=0.108, R^{2}=0.012\right)$, comfort of different ambient light levels $\left(R=0.121, R^{2}=0.015\right)$, distraction of direct task light $\left(R=0.309, R^{2}=0.095\right)$ or background walls $\left(R=0.003, R^{2}=0.8 \mathrm{E}-6\right)$, difficulty at blocking out distractions $\left(R=0.011, R^{2}=0.1 \mathrm{E}-4\right)$, fatigue level $\left(R=0.022, R^{2}=0.5 \mathrm{E}-4\right)$, overall impression of the Private Eye $\left(R=0.129, R^{2}=0.017\right)$, or emotional and/or physical condition $\left(R=0.068, R^{2}=0.005\right)$.

Table 21. Correlations between session mean scores and questionnaire responses.*

\begin{tabular}{|lc|}
\hline \multicolumn{1}{|c|}{ Question } & $\begin{array}{c}\text { Session Mean } \\
\text { Score }\end{array}$ \\
\hline Frequency of playing video games & $0.445 / 0.198$ \\
Ever played "Space Invaders" $(\mathrm{Y}=1, \mathrm{~N}=2)$ & $0.224 / 0.050$ \\
Adequacy of PE as compared to a CRT & $0.059 / 0.003$ \\
Dominant eye $(\mathrm{L}=1, \mathrm{R}=2)$ & $0.419 / 0.176$ \\
Difficulty in focusing on Private Eye & $0.465 / 0.216$ \\
Level of comfort & $0.076 / 0.006$ \\
Wear glasses/contacts $(\mathrm{Y}=1, \mathrm{~N}=2)$ & $0.108 / 0.012$ \\
More comfortable light level (Bright $=1$, Dark $=2)$ & $0.121 / 0.015$ \\
Distraction of direct task light & $0.309 / 0.095$ \\
Distraction of background walls & $0.003 / 8 \mathrm{E}-6$ \\
Difficulty at blocking out distractions' & $0.011 / 1 \mathrm{E}-4$ \\
Fatigue level at completion & $0.022 / 5 \mathrm{E}-4$ \\
Overall impression of the Private Eye & $0.129 / 0.017$ \\
Current emotional/physical condition & $0.068 / 0.005$ \\
\hline *R/R & \\
\hline
\end{tabular}




\section{Discussion}

The goal of the second experiment was to determine the effects of various local visual parameters on the ability of the user to accurately perceive the information on the Private Eye. If the ability to read the monitor was adversely affected by the level of ambient illumination or degree of background visual complexity, then its usefulness in the field would be limited. Regardless of how well the monitor can be read in controlled "office" environment, if it cannot be reliably read under the various conditions that might be found in situ, then its usefulness onboard the S.S. Freedom, is limited. Regardless of its low weight and power requirements, its small volume, and most importantly, its capacity to be worn on the head, if it cannot be reliably read under the various conditions that might be found in situ, then its usefulness onboard the S.S. Freedom is limited.

Based on the results of this second study, it would appear that the Private Eye is capable of being utilized under a variety of local visual conditions. No significant differences in operator performance were evident between bright and dark ambient illumination. Neither did a complex visual background have a detrimental effect on performance. There were also no differences based on the various combinations of these factors.

Luminous surfaces within the field-of-view did have a negative effect on performance. Under certain conditions, direct glare, reflected from the light-colored bezel surrounding the monitor, reduced the contrast ratio to the point where perceiving the contents of the display was significantly impaired. This effect was particularly pronounced for males in an otherwise dark environment. Admittedly, it took a deliberate effort on the part of the experimenter to align a point source of light to reflect off the bezel into the subject's eye and a cooperative subject not to adjust the monitor and/or head to avoid the glare. Thus, this does not appear to be a major drawback in considering the Private Eye for use in situ. However, it is a relatively easily remedied human factors concern that should be addressed.

A more concerted effort was made in the second experiment to adequately train the subjects before starting the experiment. This effort was apparently successful, as there were no significantly different scores among games within a trial or among trials within the session. In addition, all subjects indicated on the postsession questionnaire that they had received an adequate training period.

Questionnaire responses indicate a favorable judgment of the Private Eye in comparison to a "normal monitor" and a favorable overall impression of the Private Eye. In terms of subjective responses to the independent variables, subjects found the glare highly distractive. This is supported by the objective experiment data which showed a significant performance decrement with glare. Visually complex backgrounds were reported to be only moderately distractive. This, again, is supported by the experimental data which showed no differences in performance between the visually simple and complex task backgrounds. More subjects found the dark condition more comfortable (11 to 5), but no performance differences were evident in the experiment data.

Only two relatively high correlations stand out. The judged adequacy of the Private Eye vis-a-vis "normal monitors" and reported level of comfort are correlated, with over half of the variation of each "explained" by the other. This suggests that further improvements in comfort might enhance the perceived adequacy of the Private Eye.

The second relatively high correlation concerns distractions and fatigue. Neither glare nor visually complex backgrounds correlated with reported fatigue, but difficulty in blocking out distractions did. Almost two-thirds of the variation of reported fatigue is "explained" by difficulty in blocking out distractions (and vice versa). Although not directly related to the Private Eye, this 
suggests that increasing distraction tolerance (through training, desensitization, etc.) might reduce fatigue and, thus, improve productivity. This insight might be particularly beneficial for those environments that have distractions that cannot be further reduced.

\section{CONCLUSIONS}

Two studies were conducted to assess the Private Eye's capabilities and limitations. The first examined the effects of different information presentation media (Private Eye, CRT, and hard copy) and work envelope volume (constrained and unconstrained) on the performance of an identification and manual assembly task. The second study, using the Private Eye as the presentation media, examined the effects of ambient illumination, luminous surfaces in the field-of-view, and background visual complexity on the performance of an interactive animated computer task.

The first study demonstrated that the Private Eye compared favorably with both a CRT and hard copy for a task that required frequent reference to displayed information. In this study, the CRT and hard copy were placed in a near-optimal location relative to the task. In a work environment where a "normal" monitor or hard copy can be near-optimally located, there appears to be no expected performance benefit, nor loss, in choosing among the three presentation media. As the work environment becomes constrained, at least in the manner employed in this study, the use of hard copy becomes a burden. As the work environment becomes more constrained, or for that matter dynamic, both hard copy and "normal" monitors would become burdens. It is under these conditions, in particular, that the Private Eye can enhance performance.

The second study demonstrated that the Private Eye is capable of being utilized under a variety of local visual conditions. Bright or dark ambient illumination environments and/or visually simple or complex task backgrounds had no effects on performance. Direct glare off the bezel surrounding the monitor did degrade performance, but this appears to be a monitor housing design problem that can be easily overcome.

Taken together, these studies indicate that the Private Eye is an effective means of presenting information, comparable to "normal" monitors and hard copy, and can be utilized in a variety of ambient illumination conditions and task visual environments. Thus, the Private Eye seems well suited for in situ operations that require ready reference to information.

This is especially true in a microgravity environment where having both hands free for translation and restraint is desirable, and restraint locations for hard copy or monitors are few and far between. In addition, the latter would not necessarily be located in the crewmember's task-centered field-of-view. Thus, the crewmember would need to frequently turn his/her head to alternately view the task area and refer to the procedures and schematics displayed on the monitor. This increases task time and, more importantly, shakes the vestibular system. The latter often leading to "stomach awareness" and, consequently, reduced productivity.

In summary, there is a need for a head-mounted display to support onboard in situ operations. It must be comparable to "normal" monitors and/or hard copy, in terms of information display, and readable in a variety of ambient illumination conditions and task visual environments. The Private Eye appears to satisfy these requirements. 


\section{REFERENCES}

1. National Aeronautics and Space Administration: "Proceedings of the Workshop on Technology for the Space Station Evolution." Washington, DC, 1990.

2. Howard, I.P.: "The Vestibular System." In "Handbook of Perception and Human Performance," K.R. Boff, L. Kaufman, and J.P. Thomas (eds.), Wiley, New York, 1986, pp. 11-1-11-30. 

APPENDIX A

Study 1

Experiment Description

GL 22 INTENTIONALlY HIN"

23

PRECEDING PAGE BLANK NOT FILMED 


\section{STUDY 1 EXPERIMENT DESCRIPTION}

\section{EXPERIMENT OVERVIEW}

The purpose of this experiment is to examine performance on an an assembly task using three kinds of presentation media under two conditions. In this experiment, you will be asked to assemble the Drive Ya Nuts puzzle. Following a familiarization and practice period, six data collection trials will begin. The data collected during your attempts will be treated with anonymity.

The three presentation media are: the "Private Eye, a miniature monitor; a cathode ray tube (CRT); and hard copy. There will be two trials for each of the presentation media. Half of these will be performed within a confined work envelope and half will be performed in an unobstructed work envelope. Thus, a total of six assembly sequences will be attempted under these two conditions. The assembly sequence will change for every trial.

The experimenters will request that you wear a miniature monitor mounted on a headset as one form of presentation media. You should not experience any eye strain or difficulty if you follow the procedures outlined in the detailed description of the experiment.

The entire experiment is expected to last no longer than 1 hour.

The research team consists of:

1. Julie Cosper, Industrial Engineer Co-op, Man-Systems Integration Branch, 544-2806.

2. Frankie Rice, Industrial Engineer Co-op, Man-Systems Integration Branch, 544-2806.

3. Joe Hale, Man-Systems Integration Branch, 544-2193. The research is sponsored by NASA, Marshall Space Flight Center, Huntsville, Alabama.

Further instructions will follow your reading and signing the attached informed consent form. These instructions will then provide more detail on the assembly procedures and any additional information you will need. As the informed consent form indicates, you have the right to decline to participate at any point in the experiment. This includes declining to participate after reading the additional instructions. Participation is voluntary.

A member of the experimental team will answer any questions you may have. However, in cases that may affect the outcome of the experiment, the team member may delay a detailed answer until you have completed the experiment.

You are requested to refrain from discussing the experiment with other individuals who may be come subjects. We expect all data to be taken by April 13, 1990. Following that date, feel free to discuss the experiment with anyone you wish.

Finally, we want to point out that the assembly task is not difficult. The experiment is not designed to test your skill. We are only interested in how your performance may vary based on the different trial conditions. Furthermore, as indicated earlier, the data will be treated with anonymity. 
APPENDIX B

Informed Consent Form 


\section{INFORMED CONSENT FORM}

\section{PARTICIPANT'S CONSENT}

As a participant in this experiment, you have certain rights. The purpose of this form is to make you aware of these rights and to obtain your consent to participate. Your participation is voluntary.

1. You have the right to stop the experiment in which you are participating at any time if you feel that it is not agreeable to you.

2. You have the right to see your data and to withdraw it from the experiment, if you feel that you should. In general, data are processed after all runs are completed. In this experiment, we can provide you with some qualitative information immediately after the experiment. Subsequently, all data are treated with anonymity. Therefore, if you wish to withdraw your data, you must do so immediately after your participation is completed.

3. You have the right to be informed on the results of the overall experiment. If you wish to receive information on the results, please include your address with your signature below. A summary will be sent to you.

We hope you will find the experiment a pleasant and interesting experience. The research team involved greatly appreciates your help as a participant. If you have any questions about the experiment or your rights as a participant, please do not hesitate to ask. We will do our best to answer them, subject only to the constraint that we do not want to pre-bias the experimental results.

Your signature below indicates that you have read the above stated rights and that you consent to participation. If you include your printed name and address below, a summary of the experimental results will be sent to you.

\section{Signature}

Print name and address if you wish to receive a summary of the Witness' Signature experimental results. 


\section{APPENDIX C \\ Study 2 \\ Experiment Description}




\section{EXPERIMENT OVERVIEW}

The purpose of this experiment is to examine performance on an interactive, animation task under a variety of conditions. In this experiment, you will be asked to "play" Space Invaders. Following a few warm-up practice games, eight data collection trials will begin. The data collected during your trials will be treated with anonymity.

Three parameters (each with two levels) will be manipulated during this experiment with all possible combinations presented. These are: Ambient Illumination (High/Low), Luminous Surfaces in the field-of-view (Yes/No), and Background Visual Complexity (Simple/Complex). There will be a short rest period after each trial, during which the experimenter will reconfigure the lights and background for the next trial. Upon completion of the last trial, you will be asked to complete a short questionnaire. The entire experiment is expected to last approximately 90 minutes.

The research team consists of:

1. Gina Klinzak, New Technologies, Inc. , 461-6464.

2. Joe Hale, Man-Systems Integration Branch, 544-2193. The research is sponsored by NASA, Marshall Space Flight Center, Huntsville, Alabama.

Attached for you to read and sign is an informed consent form. This informs you that you have the right to decline to participate at any point in the experiment. Participation is voluntary.

A member of the experimental team will answer any questions you may have. However, in cases that may affect the outcome of the experiment, the team member may delay a detailed answer until you have completed the experiment. You are requested to refrain from discussing the experiment with other study participants until after their experiment session, as this may influence their performance in some manner.

Finally, we want to point out that the task is not difficult. The experiment is not designed to test your skill. We are only interested in how your performance may vary based on the different trial conditions. Furthermore, as indicated earlier, the data will be treated with anonymity. 


\section{APPENDIX D}

\section{Study 2 Questionnaire}




\section{Private Eye Test Questionnaire}

1. Do you play video games?

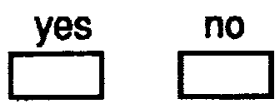

If no, skip to question 4.

2. How often do you play?

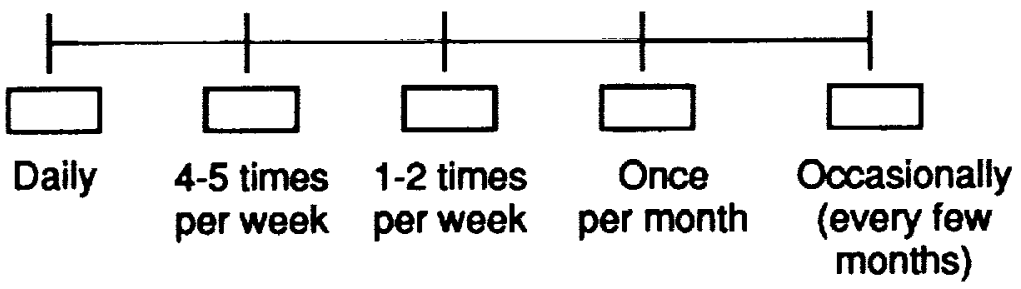

3. Have you every played Space Invaders before your training session?

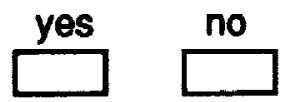

4. How would you judge your visual perception of the screen in comparison to a normal monitor?

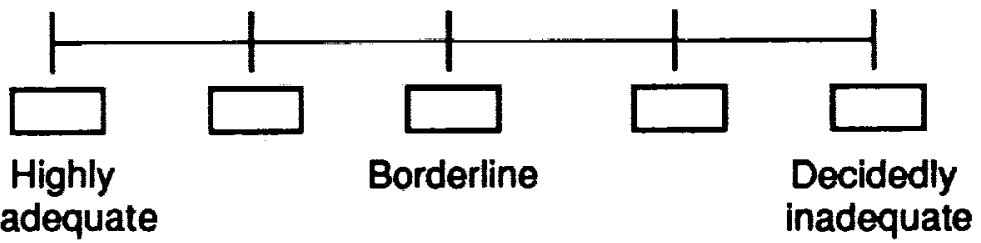

5. Which would you judge to be your dominant eye?

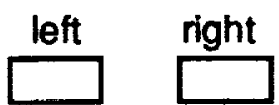

6. What was your level of difficulty in focusing on the screen?

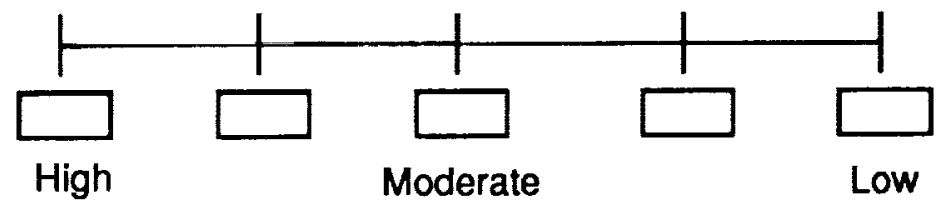

7. What would you determine to be your level of comfort?

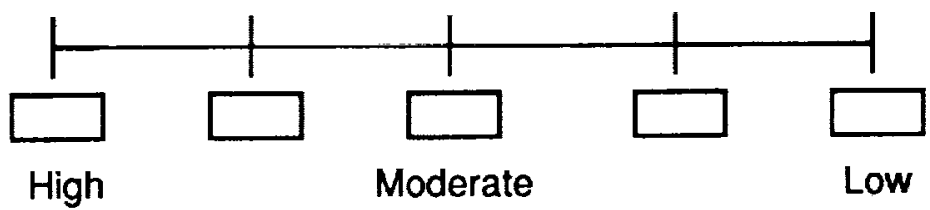




\section{Subject Number: \\ Private Eye Test Questionnaire Continued....... \\ 8. Do you wear glasses/contacts? yes no}

9. Which light level was more comfortable to you?

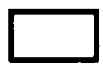

High Ambient

Illumination

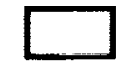

Low Ambient

Illumination

10. How would you judge the direct task light as a distraction?

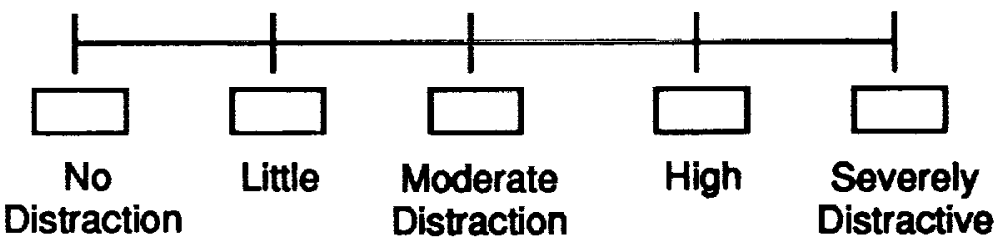

11. How would you judge the background walls as a distraction?

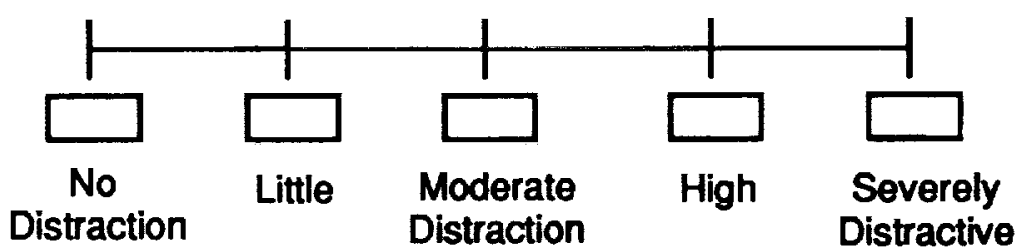

12. How much difficulty did you have in blocking out distractions?

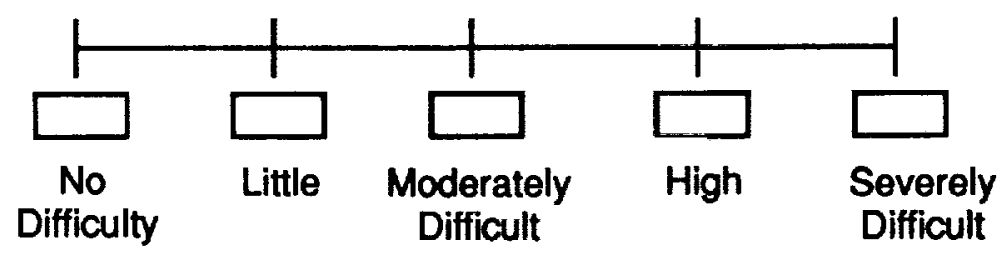

13. How would you judge your fatigue level when finished?

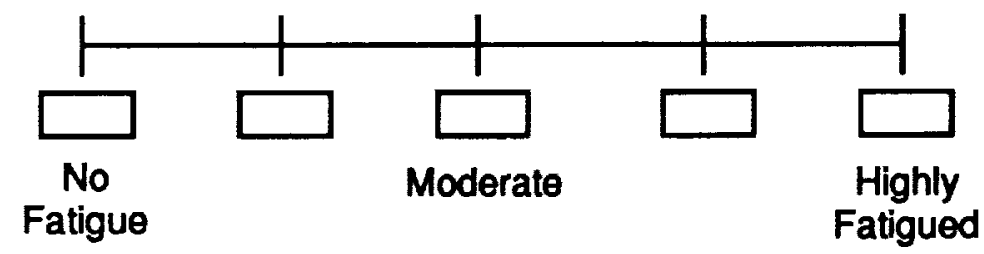




\section{Personal Observation}

What was your overall impression of the Private Eye?

$\square$ Strongly Like
$\square$ Like
$\square$ Neutral
$\square$ Don't Like
$\square$ Strongly Dislike

Do you feel you had an adequate training period?

How do you feel today (eg. emotional/physical)?

$\square$ Excellent
$\square$ Good
$\square$ Only Fair
$\square$ Poor
$\square$ Terrible

Do you have any comments or suggestions regarding the Private Eye (eg. data entry, screen display clarity, display layout)? 


\section{APPROVAL \\ ASSESSMENT OF A HEAD-MOUNTED MINIATURE MONITOR \\ By J.P. Hale II}

The information in this report has been reviewed for technical content. Review of any information concerning Department of Defense or nuclear energy activities or programs has been made by the MSFC Security Classification Officer. This report, in its entirety, has been determined to be unclassified.

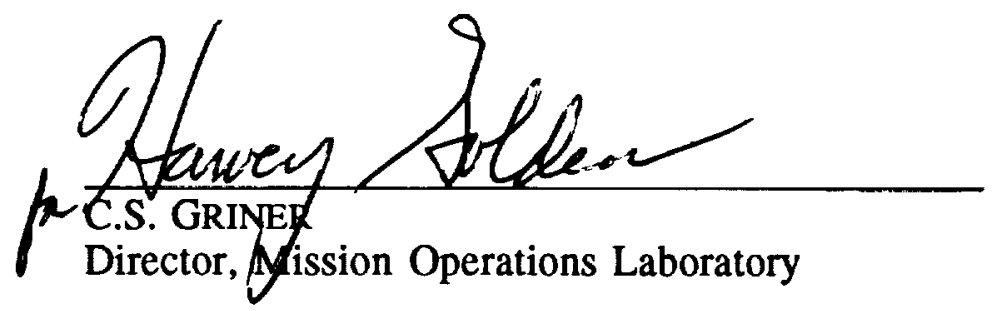

U.S. GOVERNMENT PRINTING OFFICE $1992-631-060 / 60136$ 
